\title{
Chemotherapy-Induced Pulmonary Hypertension
}

\section{Role of Alkylating Agents}

Benoît Ranchoux, ${ }^{* \dagger}$ Sven Günther, ${ }^{* \dagger \dagger}$ Rozenn Quarck, ${ }^{\S}$ Marie-Camille Chaumais, ${ }^{* \dagger}$ Peter Dorfmüller, ${ }^{* \dagger \|}$ Fabrice Antigny, ${ }^{* \dagger}$ Sébastien J. Dumas, ${ }^{* \dagger}$ Nicolas Raymond, ${ }^{* \dagger \|}$ Edmund Lau, ${ }^{* \dagger \neq}$ Laurent Savale, ${ }^{* \dagger \neq}$ Xavier Jaïs, ${ }^{* \dagger \ddagger}$ Olivier Sitbon, ${ }^{* \dagger \ddagger}$ Gérald Simonneau, ${ }^{* \dagger \neq}$ Kurt Stenmark, ${ }^{* *}$ Sylvia Cohen-Kaminsky, ${ }^{* \dagger}$ Marc Humbert, ${ }^{* \dagger \ddagger}$ David Montani, ${ }^{* \dagger \dagger}$ and Frédéric Perros ${ }^{* \dagger}$

From the Faculty of Medicine, * Université Paris-Sud, Faculté de Médecine, and the Assistance Publique des Hôpitaux de Paris (AP-HP), the Reference Center for Severe Pulmonary Hypertension, ${ }^{\ddagger}$ Pneumology and Respiratory Intensive Care Service, Hôpital de Bicêtre, Le Kremlin-Bicêtre, Paris, France; INSERM U999, ${ }^{\dagger}$ Pulmonary Arterial Hypertension: Pathophysiology and Therapeutic Innovation, Centre Chirurgical Marie Lannelongue, and the Pathology Service, Centre Chirurgical Marie Lannelongue, Le Plessis-Robinson, Paris, France; the Respiratory Division, ${ }^{\S}$ Department of Clinical and Experimental Medicine, KU Leuven, Leuven, Belgium; the AP-HP, ${ }^{\llbracket}$ Pharmacy Service, Département Hospitalo-Universitaire Thorax Innovation, Hôpital Antoine Béclère, Clamart, France; and the Department of Pediatrics, ** University of Colorado at Denver, Aurora, Colorado

Accepted for publication

October 14, 2014.

Address correspondence to Frédéric Perros, Ph.D., INSERM U999, Centre Chirurgical Marie Lannelongue, 133 Ave de la Resistance, Le Plessis-Robinson, F-92350 Paris, France. E-mail: frederic. perros@inserm.fr.
Pulmonary veno-occlusive disease (PVOD) is an uncommon form of pulmonary hypertension (PH) characterized by progressive obstruction of small pulmonary veins and a dismal prognosis. Limited case series have reported a possible association between different chemotherapeutic agents and PVOD. We evaluated the relationship between chemotherapeutic agents and PVOD. Cases of chemotherapy-induced PVOD from the French PH network and literature were reviewed. Consequences of chemotherapy exposure on the pulmonary vasculature and hemodynamics were investigated in three different animal models (mouse, rat, and rabbit). Thirty-seven cases of chemotherapy-associated PVOD were identified in the French PH network and systematic literature analysis. Exposure to alkylating agents was observed in $83.8 \%$ of cases, mostly represented by cyclophosphamide (43.2\%). In three different animal models, cyclophosphamide was able to induce $\mathrm{PH}$ on the basis of hemodynamic, morphological, and biological parameters. In these models, histopathological assessment confirmed significant pulmonary venous involvement highly suggestive of PVOD. Together, clinical data and animal models demonstrated a plausible cause-effect relationship between alkylating agents and PVOD. Clinicians should be aware of this uncommon, but severe, pulmonary vascular complication of alkylating agents. (Am J Pathol 2015, 185: 356-371; http://dx.doi.org/10.1016/j.ajpath.2014.10.021)
Pulmonary veno-occlusive disease (PVOD) is a rare subgroup of pulmonary hypertension $(\mathrm{PH})$ characterized by predominant pulmonary venous involvement. ${ }^{1}$ Although a definite diagnosis of PVOD requires histological confirmation, ${ }^{2}$ lung biopsy is often considered to be a high-risk procedure in these critically ill patients. More recently, a noninvasive approach on the basis of compatible clinical and radiological assessment can be sufficient to support a confident diagnosis of PVOD. ${ }^{3}$

The pathophysiological mechanisms of PVOD remain poorly understood. ${ }^{4}$ Several drugs have been suggested to induce PVOD and, in particular, chemotherapeutic agents,
Supported by Agence National de la Recherche grant ANR-13-JSV1-0011, Labex LERMIT (B.R.), Association HTAPFrance grant (S.G. and D.M.), Aviesan [Institut Thématique Multi-Organismes Immunologie, Hématologie et Pneumologie (ITMO IHP)] post-doctoral grant (F.A.), a Bayer Investigator Sponsored Study grant (F.P.), and Fonds de Dotation Recherche en Santé Respiratoire (S.J.D.). The French pulmonary hypertension pharmacovigilance network VIGIAPATH is chaired by M.H. and supported by the Agence Nationale de Sécurité du Médicament et des Produits de Santé.

\section{B.R. and S.G. contributed equally to this work.}

D.M. and F.P. contributed equally to this work as senior authors.

Disclosures: L.S., X.J., O.S., G.S., M.H., and D.M. have received speaker fees or honoraria for consultations from Actelion, Bayer, Bristol-Myers-Squib, GSK, Lilly, Novartis, Pfizer, and United Therapeutics Corporation; received reimbursement from Actelion and Lilly for attending French and international meetings; and received fees from Bristol-Myers-Squib and Lilly for participating to advisory boards. 
such as bleomycin, carmustine, and mitomycin, ${ }^{5-7}$ have been reported to be associated with PVOD. Moreover, bone marrow transplantation (BMT) is also considered to be a risk factor for the development of PVOD. ${ }^{8-10}$ Despite the recognition that chemotherapy can potentially provoke PVOD, no specific drug or therapeutic class has been clearly identified as a risk factor for PVOD.

The first objective of the present study was to determine the chemotherapeutic agents that could be involved in the development of PVOD. Thus, we reviewed cases of chemotherapyinduced PVOD from the French PH network and performed a systematic literature review to identify potential chemotherapeutic agents implicated in the development of PVOD. Furthermore, additional treatment, including radiotherapy and the role of BMT, was investigated. Herein, we demonstrate that alkylating agents are the predominant chemotherapeutic class associated with PVOD, with cyclophosphamide (CP) being detected in nearly half of all chemotherapy-induced PVOD cases. On the basis of this finding, we investigated the consequences of $\mathrm{CP}$ exposure on the pulmonary vasculature and hemodynamics in three different animal models (mouse, rat, and rabbit). The influences of sex, time course, and dose-response to $\mathrm{CP}$ were also evaluated. We analyzed right heart and pulmonary artery (PA) hemodynamics, morphological parameters (in heart and lungs), and biological parameters (in lungs and serum/blood cells) relevant to pulmonary vascular dysfunction and inflammation. Finally, we performed in vivo experiments on whether cytoprotective agents (mesna and amifostine) used during treatment with $\mathrm{CP}$ could prevent the development of $\mathrm{PH}$.

\section{Materials and Methods}

Identified Cases of Chemotherapy-Related PVOD in the French PH Network and in the Literature

We reviewed all cases from the French PH Registry of confirmed precapillary $\mathrm{PH}$ among patients in whom PVOD was suspected after commencement of chemotherapy, radiotherapy, and/or BMT.

The French PH Registry was established in accordance with French bioethics laws (National Commission on Informatics and Liberty) in 2004, and all included patients gave their informed consent.

Routine evaluation at baseline included demographics, medical history, physical examination, echocardiography, chest high-resolution computed tomography, ventilation/ perfusion lung scan, abdominal ultrasound, autoimmunity screening, and HIV serological test. Precapillary PH was confirmed in all cases by right heart catheterization (RHC). At diagnosis, New York Heart Association functional class and 6-minute walk distance were recorded.

Data were centrally collected and analyzed at the French referral center for severe PH (Hôpital Bicêtre, University ParisSud, Le Kremlin-Bicêtre, Paris, France).

The systematic literature review in PubMed and Medline was performed on December 1, 2013. Key words entered in the medical subject headings (MESH) database were as follows: cancer [MESH] and pulmonary veno-occlusive disease, radiotherapy [MESH] and pulmonary veno-occlusive disease and chemotherapy [MESH], and pulmonary venoocclusive disease. The chosen key words cancer, chemotherapy, and radiotherapy [MESH] were also crossed to pulmonary capillary hemangiomatosis, an entity considered to be similar to PVOD. In addition, we crossed specific chemotherapeutic agents implicated in the development of PVOD, including cisplatin, cyclophosphamide, and mitomycin [MESH] with pulmonary veno-occlusive disease. With respect to different search terms, the following number of articles were retrieved: cancer [MESH] and pulmonary veno-occlusive disease $(n=115)$, radiotherapy [MESH] and pulmonary veno-occlusive disease $(n=14)$, chemotherapy $[\mathrm{MESH}]$ and pulmonary veno-occlusive disease $(n=48)$, cancer [MESH] and pulmonary capillary hemangiomatosis $(n=62)$, chemotherapy [MESH] and pulmonary capillary hemangiomatosis $(n=2)$, and radiotherapy [MESH] and pulmonary capillary hemangiomatosis $(n=0)$. Search terms containing specific chemotherapeutic agents yielded the following: cisplatin $[\mathrm{MESH}]$ and pulmonary veno-occlusive disease $(n=$ 3), cyclophosphamide [MESH] and pulmonary veno-occlusive disease $(n=21)$, and mitomycin [MESH] and pulmonary veno-occlusive disease $(n=3)$.

\section{Analysis of Case Reports}

All identified case reports were adjudicated to determine whether a diagnosis of PVOD was compatible. This was on the basis of functional, radiological, hemodynamic, and histological data (if available) presented in each case report. Functional evaluation was on the basis of reported worsening dyspnea, as determined by the New York Heart Association functional class; radiological assessment included chest radiography and/or chest high-resolution computed tomography; and hemodynamic evaluation included echocardiographic examination and/or RHC. Two pneumologists (S.G. and D.M.) reviewed all case reports independently, and one pathologist specializing in pulmonary vascular diseases (P.D.) reviewed all histological data. Final decision on the classification of PVOD was reached by consensus, and patients were classified into the following three groups: i) confirmed PVOD, ii) highly probable PVOD, and iii) probable PVOD. Criteria for confirmed PVOD required histological proof of PVOD by either lung biopsy or post-mortem examination. Patients were considered to have highly probable PVOD if RHC confirmed precapillary PH in association with consistent radiological findings. Diagnosis of probable PVOD was given even in the absence of a histological proof or the presence of $\mathrm{PH}$ on $\mathrm{RHC}$, on the basis of clinical presentation and functional evaluation, including echocardiography.

Detailed information was recorded concerning administrated chemotherapeutic agents, including frequency and duration of exposure. Each chemotherapeutic agent was recorded once, even if administrated several times during the 
Table 1 Patients Presenting Chemotherapy-Induced Pulmonary Veno-Occlusive Disease Identified in the French Referral Center for Severe $\mathrm{PH}$

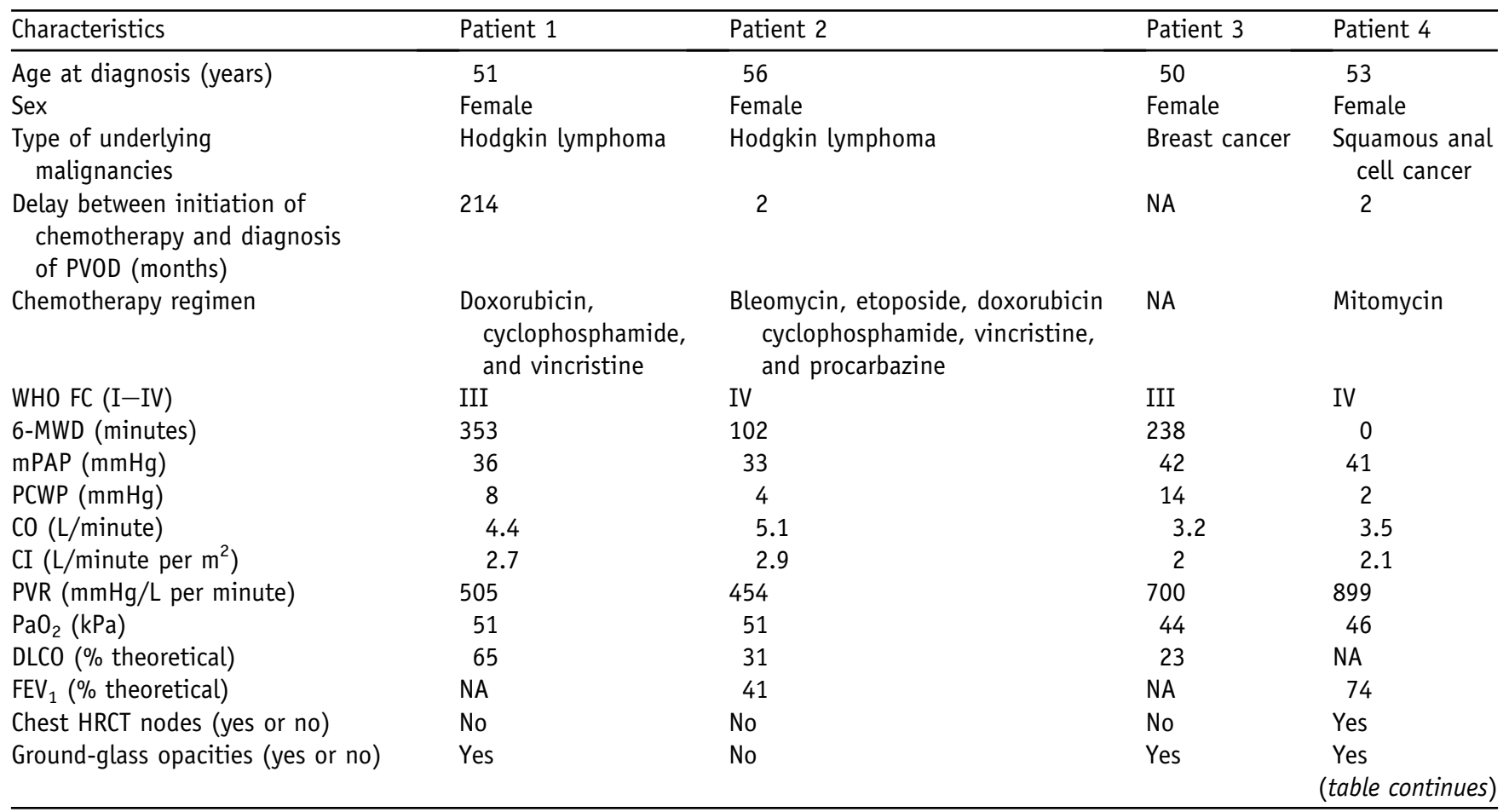

CI, cardiac index; $C 0$, cardiac output; DLCO, diffusing capacity of the lung for carbon monoxide; FC, functional class; FEV 1 , forced expiratory volume in 1 second; HRCT, high-resolution computed tomography; mPAP, mean pulmonary arterial pressure; 6-MWD, 6-minute walk distance; $\mathrm{NA}$, not available; $\mathrm{PaO}_{2}$, partial pressure of arterial oxygen; $\mathrm{PCWP}$, pulmonary capillary wedge pressure; $\mathrm{PH}$, pulmonary hypertension; PVOD, pulmonary veno-occlusive disease; PVR, pulmonary vascular resistance; WHO, World Health Organization.

course of treatment, and the agents were classified according to their therapeutic group. Other treatments consisted of radiotherapy and BMT, including graft-versus-host disease prophylaxis. The site, cumulative dose (in Gy), and frequency of radiotherapy were noted. Similarly, drugs used for graft-versus-host disease prophylaxis were recorded once even if administrated several times in the course of treatment.

\section{Chemotherapies and Associated Therapy (Radiotherapy and BMT)}

All patients were treated with various chemotherapeutic regimens, depending on the type, stage, and severity of underlying cancer. In addition, frequency of chemotherapy, dose administration, and each cycle of chemotherapy were different. Therefore, we decided to note each substance only once, even if administrated several times in the course of disease.

\section{In Vivo Study Design}

We exploited three different animal models (mice, rats, and rabbits) to assess the pathobiological characteristics of the in vivo models of CP-induced PVOD. Rodents and rabbits were used because of their established utility as animal models of PH in cardiovascular research. However, there is pronounced interspecies variation in the anatomy and structure of the pulmonary veins. Rodents have muscular pulmonary veins, whereas human pulmonary veins contain thin fibrous walls. Given the greater similarity in the structure of pulmonary veins between rabbits and humans, we also injected rabbits with $\mathrm{CP}^{11}$ (Endoxan; Baxter, Deerfield, IL) to compare the histopathological features of PVOD between human and animal after alkylating agent exposure.

Mice and rats were housed at the Faculty of Pharmacy of Châtenay-Malabry (ANIMEX platform, Châtenay Malabry, France). Experiments were conducted according to the European Union regulations (European Economic Community Directive 86/609) for animal experiments and complied with our institution's guidelines for animal care and handling. The animal facility is licensed by the French Ministry of Agriculture (agreement number B92-019-01). This study was approved by the Committee on the Ethics of Animal Experiments CEEA26 CAP Sud. Mouse and rat experiments were supervised by F.P. (agreement delivered by the French Ministry of Agriculture for animal experiment number A92-392). All efforts were made to minimize animal suffering. Rabbits were housed at the Catholic University of Leuven (KU Leuven, Leuven, Belgium). The study of the potential toxic effects of $\mathrm{CP}$ on the rabbit pulmonary vasculature was approved by the Animal Ethics Committee of the KU Leuven (license number LA1210263). All animals were maintained in a temperaturecontrolled room with a 12/12-hour light/dark cycle. 
Table 1 (continued)

\begin{tabular}{|c|c|c|c|c|c|}
\hline Patient 5 & Patient 6 & Patient 7 & Patient 8 & Patient 9 & Patient 10 \\
\hline 60 & 47 & 42 & 66 & 51 & 55 \\
\hline Female & Male & Female & Male & Female & Female \\
\hline Acute myelocytic leukemia & $\begin{array}{l}\text { Squamous anal } \\
\text { cell cancer }\end{array}$ & $\begin{array}{l}\text { Squamous anal } \\
\text { cell cancer }\end{array}$ & $\begin{array}{l}\text { Squamous lung } \\
\text { cell cancer }\end{array}$ & $\begin{array}{l}\text { Squamous anal } \\
\text { cell cancer }\end{array}$ & Breast cancer \\
\hline 5 & 2 & 4 & 8 & 2 & 172 \\
\hline III & III & III & IV & IV & III \\
\hline 293 & 374 & 267 & 115 & 0 & 335 \\
\hline 45 & 43 & 39 & 38 & 64 & 50 \\
\hline 6 & 8 & 5 & 8 & 15 & 9 \\
\hline 73 & 59 & NA & 63 & 53 & 63 \\
\hline 50 & 16 & 30 & 20 & 36 & 29 \\
\hline 112 & 48 & 71 & NA & 78 & 99 \\
\hline No & Yes & No & No & No & Yes \\
\hline Yes & Yes & No & Yes & Yes & No \\
\hline
\end{tabular}

Mice

Male and female C57BL/6J mice (Janvier, 7 to 10 weeks old) were randomly divided into saline-treated control group (control; $n=17$ ) and CP-exposed group (350 mg/kg i.p., $\mathrm{CP} ; n=60)$. We performed hemodynamic measurements and tissue collection 4 weeks after injection.

\section{Rats}

Male and female Wistar rats (Janvier, 8 weeks old) were subject to different protocols to evaluate sex differences, kinetics, dose-response relationship, and effects of cytoprotective agents on $\mathrm{CP}$ exposure. Both male and female rats were used in protocol 1 (see below). Subsequently, only females were used because of their higher susceptibility to the development of $\mathrm{PH}$ after $\mathrm{CP}$ injection (protocols 2 to 5 ).

Protocol 1. Sex-specific susceptibility. Male and female rats were randomly divided into saline (control, $n=5$ ) or CP-exposed groups [Endoxan (Baxter), $350 \mathrm{mg} / \mathrm{kg}$, i.p.,
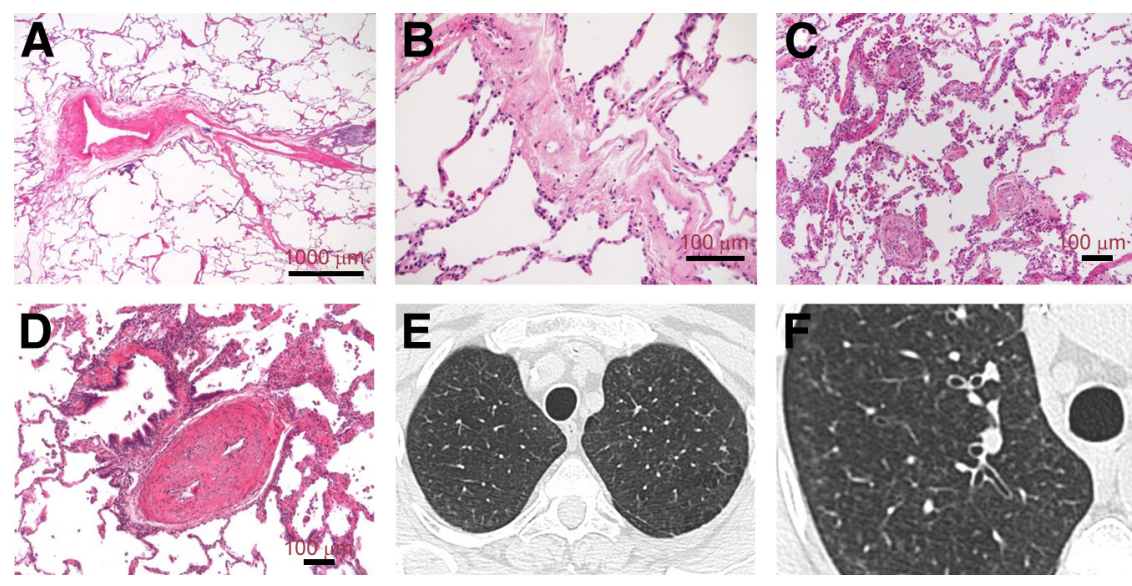

Figure 1 Histological characteristics from a patient with cyclophosphamide-associated pulmonary veno-occlusive disease (PVOD). A: Septal vein displaying significant muscularization and intimal thickening. B: Small preseptal vein with nearocclusive collagen-rich fibrosis. C: Numerous microvessels (arterioles or venules) show significant concentric muscularization. Note accumulations of siderin-laden intra-alveolar macrophages. D: Pulmonary artery (with adjacent bronchiole) displaying significant remodeling, more precisely hypertrophy of the media and intimal fibrosis. A-D: Hematoxylin and eosin stain. E and F: High-resolution computed tomography of the chest showing septal lines and centrilobular ground-glass opacities, suggestive of PVOD. 
Table 2 Identified Cases of Chemotherapy-Induced Pulmonary Veno-0cclusive Disease in the Literature with Detailed Information about Age, Sex, Underlying Malignancies, and Type of Chemotherapy

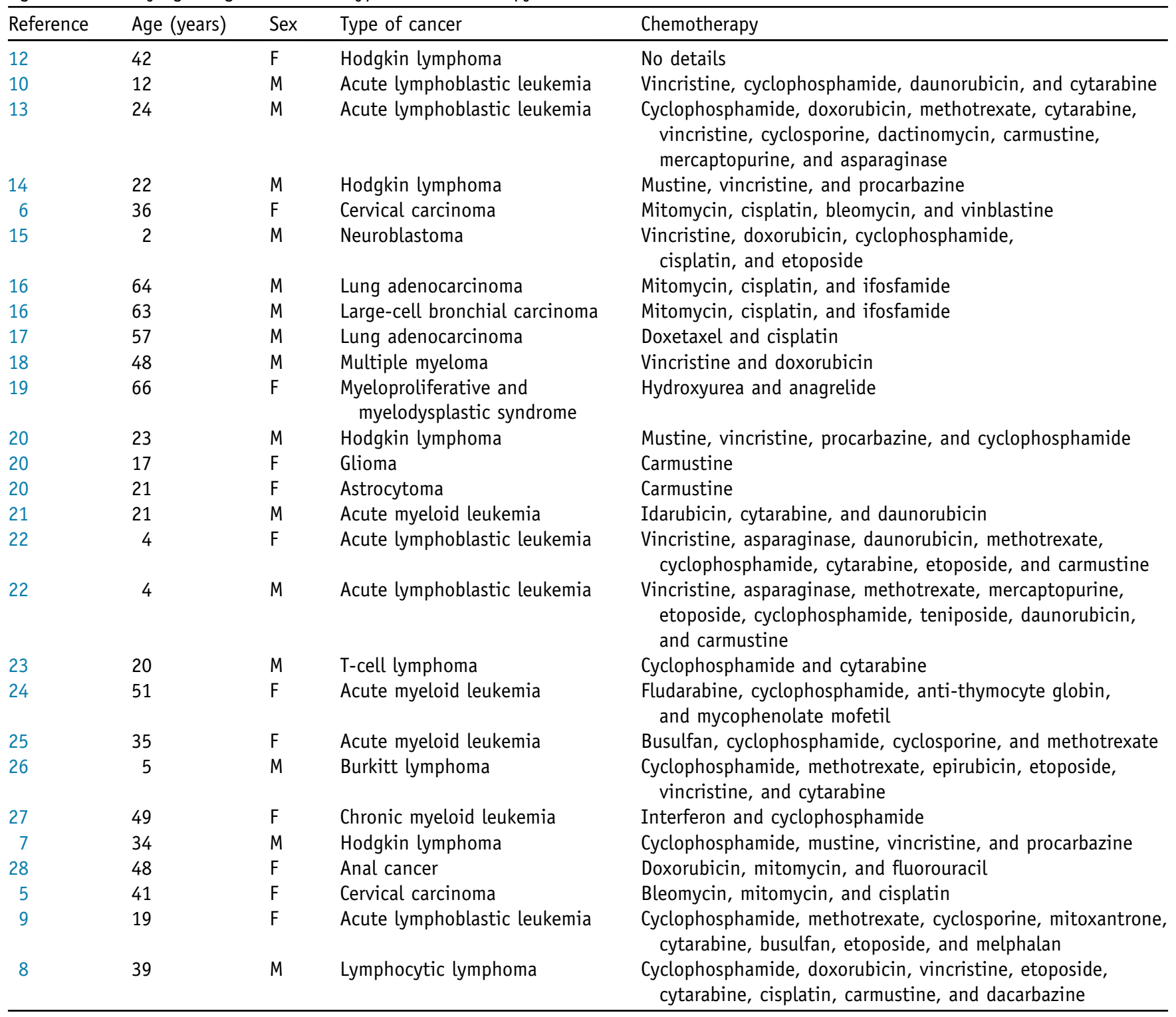

F, female; $M$, male.

$n=10]$. We performed hemodynamic measurements, right ventricle hypertrophy $(\mathrm{RVH})$ assessment, and tissue collection 4 weeks after injection.

Protocol 2. Kinetics of PH development. Female rats were randomly divided into saline (control, $n=10$ ) or CP-exposed groups (350 mg/kg, i.p., $n=40)$. We performed hemodynamic measurements, RVH assessment, and tissue collection at 1, 2, 3, and 4 weeks after $\mathrm{CP}$ injection ( $n=6$ to 10 rats for each time point).

Protocol 3. Dose-response relationships. Female rats were randomly divided into saline (control, $n=5$ ) or CP-exposed groups: $100,150,200$, and $250 \mathrm{mg} / \mathrm{kg}$ per week $/ 2$ weeks $(2 \times 100,2 \times 150,2 \times 200$, and $2 \times 250$, respectively; $n=5$ for each dose) with sacrifice at 4 weeks after the second injection for hemodynamic measurements, RVH assessment, and tissue collection. No rat survived to 4 weeks at the peak dose of $250 \mathrm{mg} / \mathrm{kg}$ per week/2 weeks $(2 \times 250)$.

Protocol 4. Prevention study. Amifostine was given i.p. at $200 \mathrm{mg} / \mathrm{kg} 30$ minutes before $200 \mathrm{mg} / \mathrm{kg}$ per week $/ 2$ weeks of CP $(n=20)$. Mesna was given as i.p. injections at a dosage equal to $20 \%$ of CP dose at the time of administration, 4 hours after each $\mathrm{CP}$ dose, and 8 hours after each $\mathrm{CP}$ dose $(n=20)$. These two groups were compared to saline (control, $n=10$ ) and CP only-exposed (CP, 200 $\mathrm{mg} / \mathrm{kg}$ per week $/ 2$ weeks, $n=20$ ) groups. Survival was evaluated over 4 weeks in the three CP-exposed groups. 
Table 3 Chemotherapeutic Agents and Molecules Identified in 37 PVOD Patients from the French PH Network and Literature Analysis

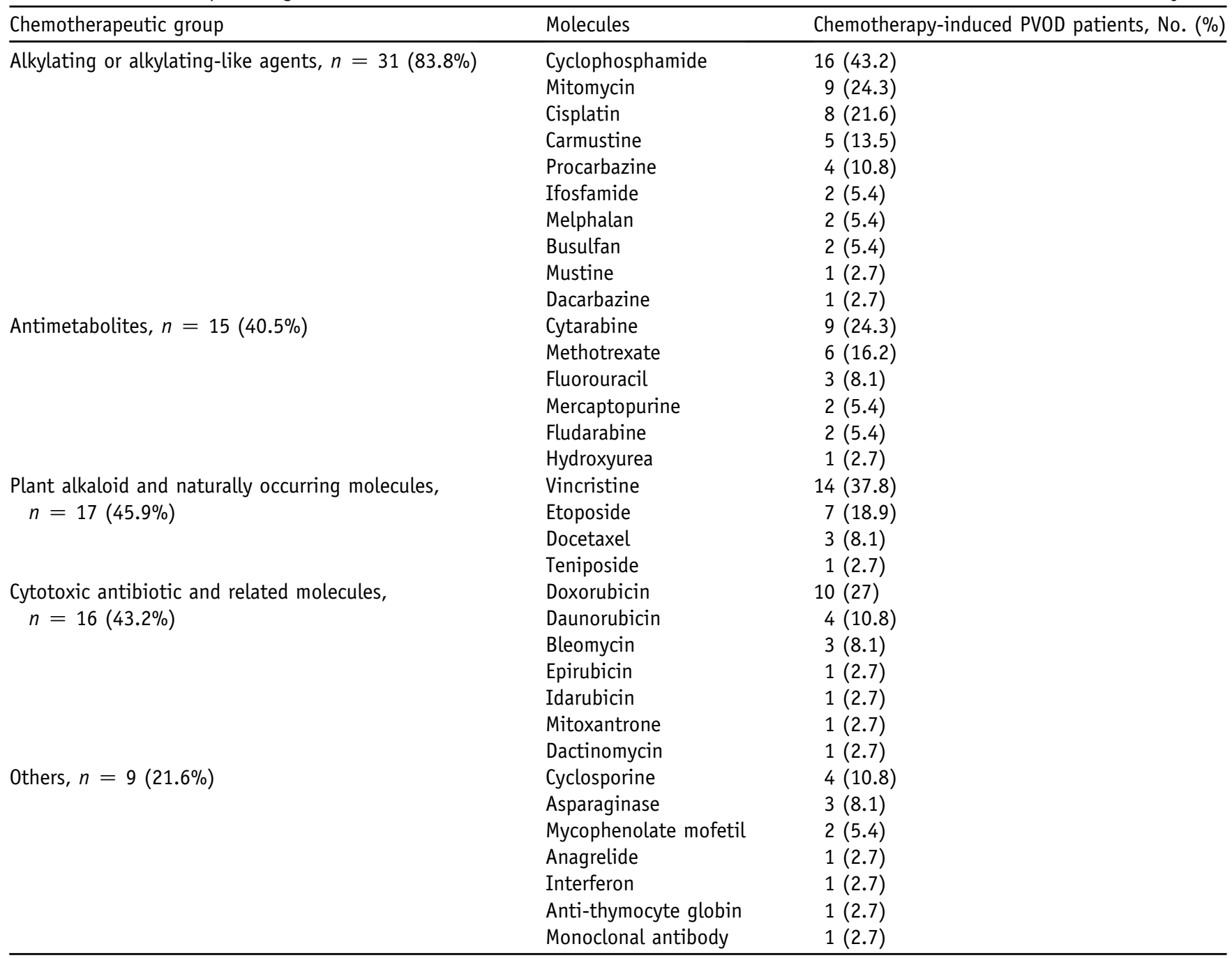

$\mathrm{PH}$, pulmonary hypertension; PVOD, pulmonary veno-occlusive disease.

Survivors were sacrificed 4 weeks after the second $\mathrm{CP}$ injection for hemodynamics, RVH measurements, and tissue collection.

Protocol 5. Long-term CP exposure. We used a lower dose of $\mathrm{CP}(100 \mathrm{mg} / \mathrm{kg})$, allowing repeated injections of CP without premature death because of early heart failure. CPs were injected i.p. at $0,1,5,6,10$, and 11 weeks and sacrificed at 13 weeks after the start of this study $(n=6)$.

\section{Rabbits}

Adult female New Zealand rabbits ( 2.5 to $3 \mathrm{~kg}$ ) were obtained from the animal facility (KU Leuven). All rabbits were housed individually (surface, $0.36 \mathrm{~m}^{2}$ ) under controlled conditions: room temperature of $18^{\circ} \mathrm{C}$ to $21^{\circ} \mathrm{C}$, 12/12-hour light/dark cycle, free access to water, standard rabbit chow once a day, and dry grass once a week.

$\mathrm{CP}$ injection: Preoperative analgesia was induced by an i.m. injection of $25 \mathrm{mg} / \mathrm{kg}$ ketamine (Anesketin; Eurovet,
Heusden-Zolder, Belgium) and $0.5 \mathrm{mg} / \mathrm{kg}$ medetomidine (Domitor; Janssen Pharmaceutica, Beerse, Belgium). During the entire procedure, animals were supplied with oxygen through a mask, maintained on a heating pad, and heart rate and blood oxygen saturation were continuously monitored using a pulse oximeter (GE Carescape V100; Uno, Zavenaar, the Netherlands) placed over the right ear central artery. Arterial blood was collected from the ear central artery, and plasma was isolated and stored at $-80^{\circ} \mathrm{C}$. CP $(100 \mathrm{mg} / \mathrm{kg})$ reconstituted in $0.9 \% \mathrm{NaCl}$, previously warmed at $37^{\circ} \mathrm{C}$, was injected i.p. Medetomidine-induced sedation was reversed by an i.m. injection of $1 \mathrm{mg} / \mathrm{kg}$ atipamezole (Antisedan; Elanco, Brussels, Belgium). When eye and pedal reflexes were observed, the animals were returned to their individual cages.

Rabbits were injected with CP $(n=6)$ or saline $(n=4)$ at 0,1 , and 3 weeks and sacrificed at 8 weeks after the first injection for RVH measurement and tissue collection. 
A

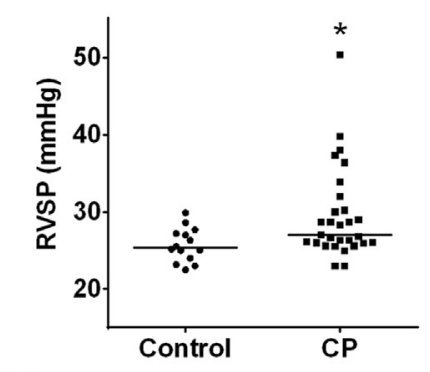

D

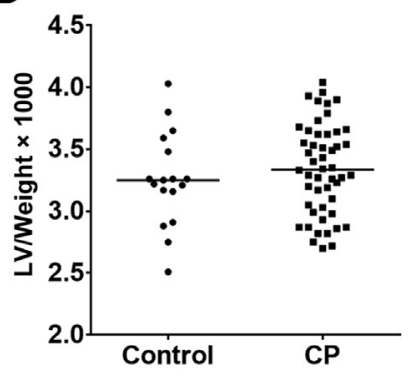

B

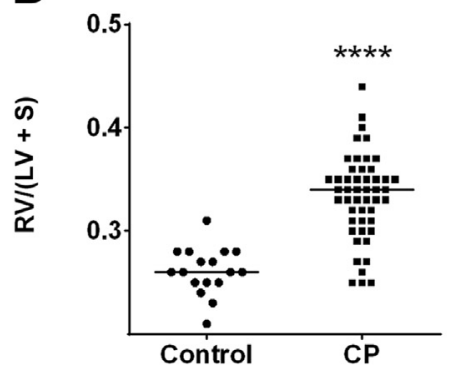

E

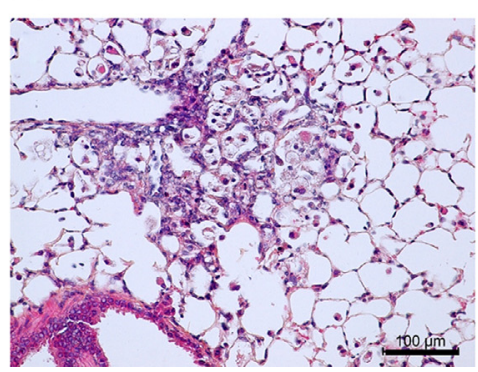

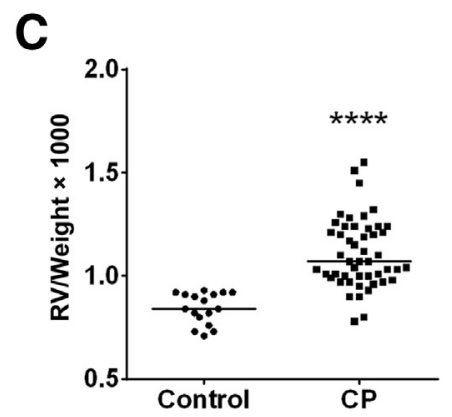

$\mathbf{F}$

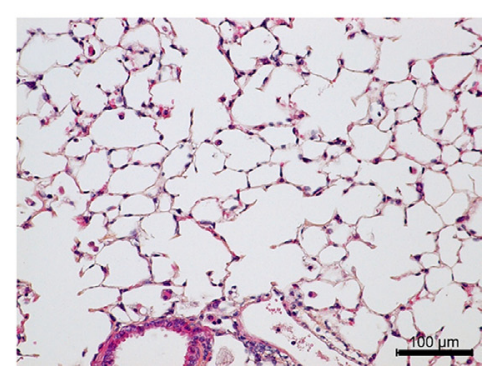

Figure 2 Cyclophosphamide (CP) induces pulmonary hypertension ( $\mathrm{PH})$ and right heart hypertrophy in mice. A: A single $350 \mathrm{mg} / \mathrm{kg} \mathrm{CP}$ exposure induces a significant increase in the right ventricular systolic pressure (RVSP) measured at 4 weeks after exposure. Control, $n=14$; CP-exposed mice, $n=29$. Because of a technical issue measuring RVSP in mice, many values are missing, especially for the most diseased animals that were more susceptible to heart arrest during the procedure. B: $\mathrm{PH}$ is associated with a compensatory right ventricle hypertrophy (RVH) quantified by the Fulton index [right ventricle (RV)/left ventricle (LV) + septum (S) weight ratio]. CP macroscopic heart effect is specific to the right side of the heart as the ratio of RV/body weight significantly increases (C), whereas the ratio of $\mathrm{LV} /$ body weight is unchanged (D). B-D: Control, $n=17$; CP-exposed mice, $n=49$. Four weeks after CP exposure, PH is associated with foci of septal thickening and accumulation of large foamy intra-alveolar macrophages $(\mathbf{E})$ that are absent in nonexposed mice $(\mathbf{F})$ (hematoxylin and eosin). ${ }^{*} P<0.05$, $* * * * P<0.0001$

Hemodynamic Measurements, RVH Evaluation, and Tissue Collection

Mice and rats were both anesthetized with $2 \mathrm{~L} /$ minute $\mathrm{O}_{2} / 3 \%$ isoflurane (Minerve, Esternay, France). Hemodynamic measurements were recorded with a PowerLab 4/35 data acquisition system and analyzed with LabChart 7 software version 7.3.1 (ADInstruments, Oxford, UK).

Right ventricle systolic pressure was measured in anesthetized mice by transthoracic puncture.

In anesthetized rats, ventral tail artery blood sampling for serum collection was performed before hemodynamic measurements. A 3.5-French umbilical vessel catheter (Tyco, Plaisir, France) was introduced into the right external jugular vein. With the angle directed anteriorly, the catheter was inserted $2.5 \mathrm{~cm}$ proximally into the right atrium. The catheter was then rotated 90 degrees anticlockwise and advanced $1 \mathrm{~cm}$ distally into the right ventricle (RV) and finally into the PA after an additional $1.5-\mathrm{cm}$ advancement. Correct anatomical placement was confirmed by respective pressure contours. A T-type Ultra Fast Thermocouple Probe (IT-23; ADInstruments, Oxford, UK) was inserted into the left carotid artery to allow measurement of cardiac output (CO) by the thermodilution technique, after injection of cold saline into the PA. Data of mean PA pressure (in $\mathrm{mmHg}$ ), $\mathrm{CO}$ (in $\mathrm{mL} /$ minute), and total pulmonary resistances (TPRs; in $\mathrm{mmHg} / \mathrm{mL}$ per minute) were subject to statistical analyses.

After exsanguination of animals (mice, rats, and rabbits), the hilum of the left lung was ligated and the right lung was distended by infusion of formalin via the trachea, and then embedded in paraffin. The noninflated left lungs were snap frozen in liquid nitrogen and used for protein and mRNA extractions and quantifications. For Fulton's index of RVH, the ratio of the right ventricular weight/left ventricular plus septal weight $(\mathrm{RV} / \mathrm{LV}+\mathrm{S})$ was calculated.

\section{Quantification of Pulmonary Microvessel Neomuscularization}

Paraffin-embedded lungs were divided into sections $(5 \mu \mathrm{m}$ thick) and stained in double immunofluorescence, for von Willebrand factor (vWF; Dako, Glostrup, Denmark) and $\alpha$-smooth muscle actin ( $\alpha$-SMA; clone 1A4; Sigma-Aldrich, Lyon, France). Pulmonary microvessels (40 to $60 ;<50 \mu \mathrm{m}$ thick) were analyzed and categorized as muscularized when $\mathrm{vWF}^{+}$endothelial cells in microvessels were coated with $\alpha$ $\mathrm{SMA}^{+}$smooth muscle cells when vessels contained at least one cell that was positive for $\alpha$-SMA but lacked a continuous layer or nonmuscularized (NM) in the absence of this coating, to assess the degree of muscularization of these normally NM precapillary and post-capillary vessels. 

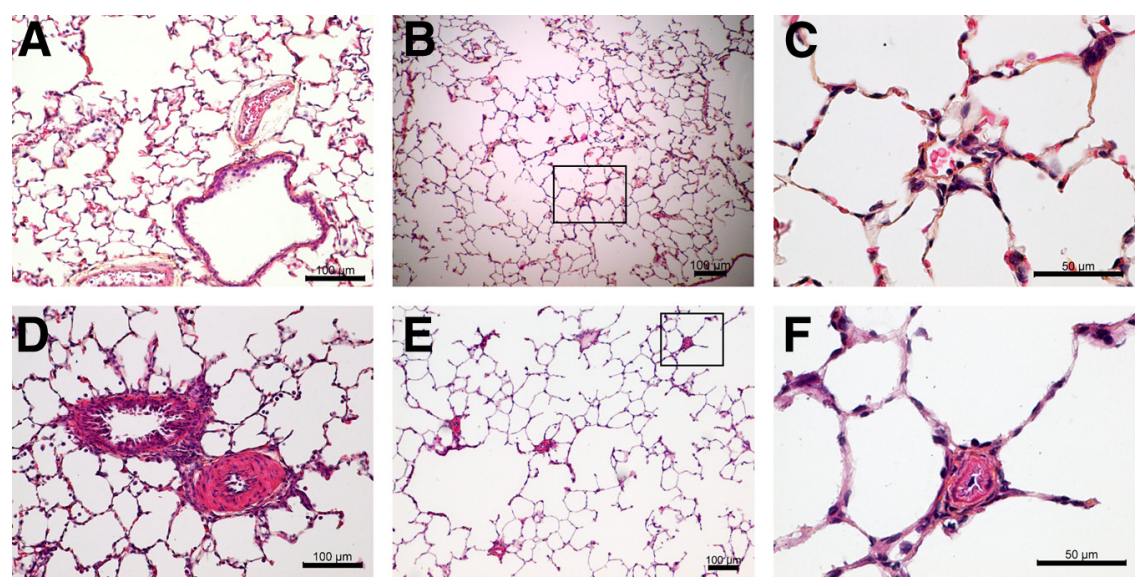

Figure 3 Cyclophosphamide (CP) induces severe pulmonary hypertension in rats linked to an intense remodeling of the distal pulmonary vasculature. A-C: Control lungs. D-F: CP-exposed lungs. $\mathbf{A}$ and $\mathbf{D}$ : Peribronchial muscular pulmonary arteries. B and E: Large overview of parenchymal/capillary bed of the lung. $\mathbf{C}$ and $\mathbf{F}$ : High magnification of precapillary/post-capillary vessels. CP-exposed rats have distal muscularization of normally nonmuscularized microvessels (venules and arterioles; D and $\mathbf{F}$ ), which is associated with medial hypertrophy of more proximal muscularized pulmonary arteries (D). Hematein-eosin-safran stain was used. Boxed areas in $\mathbf{B}$ and $\mathbf{E}$ correspond to highermagnification images in $\mathbf{C}$ and $\mathbf{R}$, respectively.

\section{Histological and Special Stains}

Hematein-eosin-safran and orcein stains were applied on paraffin lung sections (5 $\mu \mathrm{m}$ thick) following routine procedure.

\section{Flow Cytometry}

A no-lyse no-wash immunophenotyping of blood leukocytes was performed during the kinetics of $\mathrm{PH}$ development after single exposure to $\mathrm{CP}$ in rats with the triple-color reagent (CD3/CD45RA/CD161) from AbD Serotec (Oxford, UK). Flow cytometry was performed on a MACSQuant analyzer (Miltenyi, Paris, France). During the acquisition, nucleated blood leukocytes were gated in the Hoechst-positive fraction of events. The data were analyzed using the MACSQuantify software version 2.5 (Miltenyi).

\section{Multiplex Data}

We performed simultaneous quantification of recognized serum biomarkers of cardiovascular diseases in sera from control and CP-exposed rats with Millipore's MILLIPLEX (Millipore, Molsheim, France). The MILLIPLEX MAP Rat Cardiovascular Panel 1 (Millipore) was used for the simultaneous quantification of B-type natriuretic peptide, IL-6, monocyte chemoattractant protein-1, myeloperoxidase, plasminogen activator inhibitor 1 , tissue inhibitor of matrix metalloproteinases type $\mathrm{I}$, tumor necrosis factor $\alpha$, troponin I, troponin T, vascular endothelial growth factor, and vWF. The MILLIPLEX MAP Rat Cardiovascular Panel 2 (Millipore) was used for the simultaneous quantification of soluble E-selectin and soluble intercellular adhesion molecule 1. MILLIPLEX plates were washed with a Bio-Plex Pro II Wash Station (Biorad, Marnes-laCoquette, France) and read with a Luminex 200 (Millipore). Data were analyzed with the Bioplex manager software version 6.1 (Biorad). MILLIPLEX experiments were performed at INSERM IFR 65 (Saint Antoine Hospital, Paris, France).

\section{Western Blot Analysis}

Lung tissue samples from rat were prepared in lysis buffer containing $1 \%$ Igepal, $20 \mathrm{mmol} / \mathrm{L}$ Tris- $\mathrm{HCl}, 137 \mathrm{mmol} / \mathrm{L}$ $\mathrm{NaCl}, 10 \%$ glycerol, $2 \mathrm{mmol} / \mathrm{L}$ EDTA, $1 \mathrm{mmol} / \mathrm{L} \mathrm{Na}_{3} \mathrm{VO}_{4}, 10$ $\mu \mathrm{g} / \mu \mathrm{L}$ leupeptin, $10 \mu \mathrm{g} / \mu \mathrm{L}$ pepstatin $\mathrm{A}, 10 \mu \mathrm{g} / \mu \mathrm{L}$ aprotinin, and PefaBloc protease inhibitor cocktail (aprotinin, leupeptin, and PefaBloc; Roche, Meylan, France; other lysis buffer components come from Sigma-Aldrich). Protein lysates [ $40 \mu \mathrm{g}$ for the potassium channel subfamily $\mathrm{K}$, member 3 (KCNK3), and $10 \mu \mathrm{g}$ for CD45 detection] were separated onto SDSPAGE and transferred to a polyvinylidene difluoride membrane. After blocking, membranes were incubated in Trisbuffered saline and Tween 20 and 5\% nonfat milk overnight at $4{ }^{\circ} \mathrm{C}$ with primary antibodies: rabbit anti-KCNK3 (dilution 1:300; Abcam, Cambridge, UK), mouse anti-CD45 (dilution 1:1000; BD Biosciences, Le Pont de Claix, France), and mouse anti- $\beta$-actin (dilution 1:2000; Sigma-Aldrich, Lyon, France). Blots were incubated with horseradish peroxidase-conjugated goat anti-mouse (dilution 1:10,000; Cell Signaling, Danvers, MA) or with horseradish peroxidase-conjugated goat antirabbit (dilution 1:5000; Cell Signaling), accordingly. Blots were revealed using electrochemiluminescence reagents (Perkin Elmer, Villebon sur Yvette, France). ImageJ software version 1.48 (NIH, Bethesda, MD) was used to quantify the level of protein expression.

\section{Determination of Pulmonary Serotonin Levels Using Liquid Chromatography/Tandem Mass Spectrometry}

\section{Preparation of Standards}

Stock solutions of serotonin (Sigma-Aldrich) and serotoninD4, used as internal standards (Cluzeau Info Labo, SainteFoy-La-Grande, France), were prepared at a concentration of $10 \mathrm{mg} / \mathrm{mL}$ in distilled water. They were then diluted as working solutions in $100 \mathrm{mmol} / \mathrm{L}$ ammonium formate (buffered with formic acid at $\mathrm{pH}=3.5$ ) at concentrations of 1 and $3 \mu \mathrm{g} / \mathrm{mL}$, respectively. The internal standard was included in the sample before extraction. 

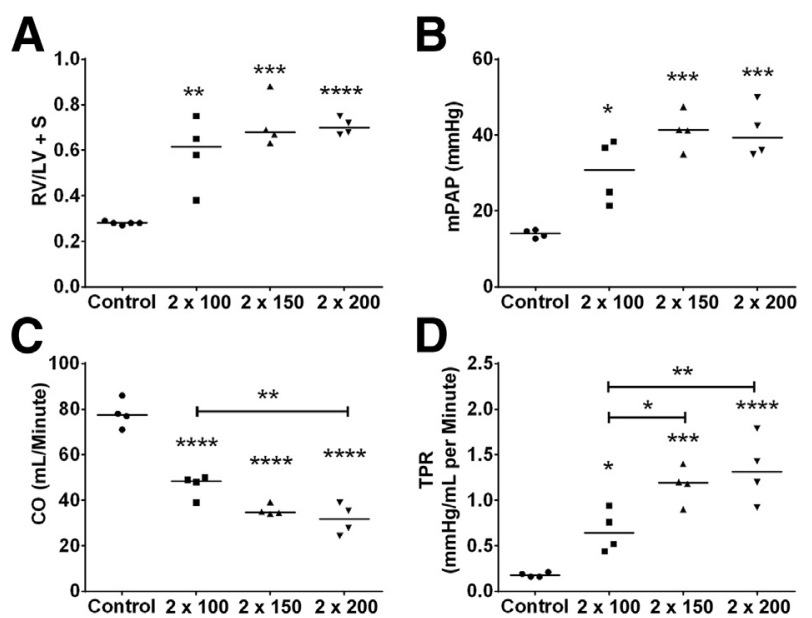

Figure 4 Cyclophosphamide (CP) induces pulmonary hypertension (PH) in a dose-dependent manner. Dose-response study with fractioned lower doses of CP in female rats: 100,150, 200, and $250 \mathrm{mg} / \mathrm{kg}$ per week for 2 weeks $(2 \times 100,2 \times 150$, and $2 \times 200$, respectively), with sacrifice 4 weeks after the second injection. No rat survived to $250 \mathrm{mg} / \mathrm{kg}$ per week for 2 weeks $(2 \times 250)$ until 4 weeks. Hemodynamic parameters and right heart hypertrophy were evaluated. A: Fulton index [right ventricle (RV)/left ventricle (LV) + septum (S) weight ratio]. B: Mean pulmonary artery pressure (mPAP; in $\mathrm{mmHg}$ ). C: Cardiac output (CO; in $\mathrm{mL} /$ minute). D: Total pulmonary resistances (TPRs; in $\mathrm{mmHg} / \mathrm{mL}$ per minute). ${ }^{\star} P<0.05$, $* * P<0.01,{ }^{* * *} P<0.001$, and $* * * * P<0.0001$.

\section{Sample Preparation for Liquid Chromatography/Tandem Mass Spectrometry}

The extraction solution was composed of $10 \% 100 \mathrm{mmol} / \mathrm{L}$ ammonium formate ( $\mathrm{pH} 3.5$ ), $10 \% 3 \mu \mathrm{g} / \mathrm{mL}$ serotonin-D4 solution, and $80 \%$ acetonitrile, allowing metabolite extraction and protein precipitation. Pieces of frozen lungs from rats were weighed (approximately $50 \mathrm{mg}$ ) and homogenized into $1 \mathrm{~mL}$ of extraction solution using GentleMACS dissociator (Miltenyi Biotech, Paris, France). The homogenates were then centrifuged at $1500 \times g$ for 5 minutes at $4^{\circ} \mathrm{C}$ to discard macroscopic residues. The supernatants were collected and submitted to two successive centrifugations at $15,000 \times g$ for 10 minutes at $4^{\circ} \mathrm{C}$ to further eliminate small residues. Supernatants were collected after each centrifugation to achieve a clear solution and then stored at $-20^{\circ} \mathrm{C}$ until use.

\section{Liquid Chromatography/Tandem Mass Spectrometry Data}

Each standard (serotonin and serotonin-D4 solutions) and extracts $(10 \mu \mathrm{L})$ were injected in a high-performance liquid chromatographic instrument (Ultimate 3000 DGP3600; Dionex, Sunnyvale, CA) with an automatic injector WPS 3000 set at $4^{\circ} \mathrm{C}$. Separation of metabolites was performed using a Nucleoshell Hydrophilic Interaction Liquid Chromatography (HILIC) column $(100 \times 2 \mathrm{~mm}, 2.7 \mu \mathrm{m}$ particle size; MachereyNagel, Hoerd, France). The mobile phase, composed of acetonitrile/100 mmol/L ammonium formate ( $\mathrm{pH} 3.5), 80 / 20(\mathrm{v} / \mathrm{v})$, was used at a flow rate of $400 \mu \mathrm{L} /$ minute. The run time was 4.5 minutes for each sample. The retention time was 1 minute for both serotonin and serotonin-D4.

Detection of serotonin was achieved with a triplequadruple mass spectrometer (Waters, Milford, MA) using an electrospray ionization source. The source and desolvation gas temperatures were set to $120^{\circ} \mathrm{C}$ and $350^{\circ} \mathrm{C}$, respectively. Desolvation gas flow was set to $479 \mathrm{~L} /$ hour; and capillary and cone voltages, $2.5 \mathrm{kV}$ and $35 \mathrm{~V}$, respectively. Multiple reaction monitoring was used in positive mode to detect precursor ions of serotonin at m/z 177 and serotonin-D4 at $\mathrm{m} / \mathrm{z}$ 181. Applying collision energies of 10 and $11 \mathrm{eV}$, product ions were obtained at m/z 160 and 164 for serotonin and serotonin-D4, respectively.

\section{Semiquantitative Analysis}

Peaks of serotonin and internal standard serotonin-D4 were integrated, and the variability of extraction rates was corrected, calculating the ratio between peak areas of serotonin and serotonin-D4. Then, these ratios were divided by the weight of lung pieces.

\section{Plasma Endothelin Quantification by Enzyme-Linked Immunosorbent Assay}

Endothelin-1 levels were measured in rabbit plasma samples using a QuantiGlo Endothelin-1 immunoassay, per the manufacturer's instructions (R\&D Systems, Lille, France).

\section{Statistical Analysis}

Unless otherwise expressed, quantitative variables were presented as means \pm SEM. Between groups, comparisons were made with paired or unpaired Student's $t$-test or MannWhitney test (comparison between two groups), analysis of variance, or Kruskal-Wallis test (comparison between more than two groups), followed by Tukey's or Dunn's test,
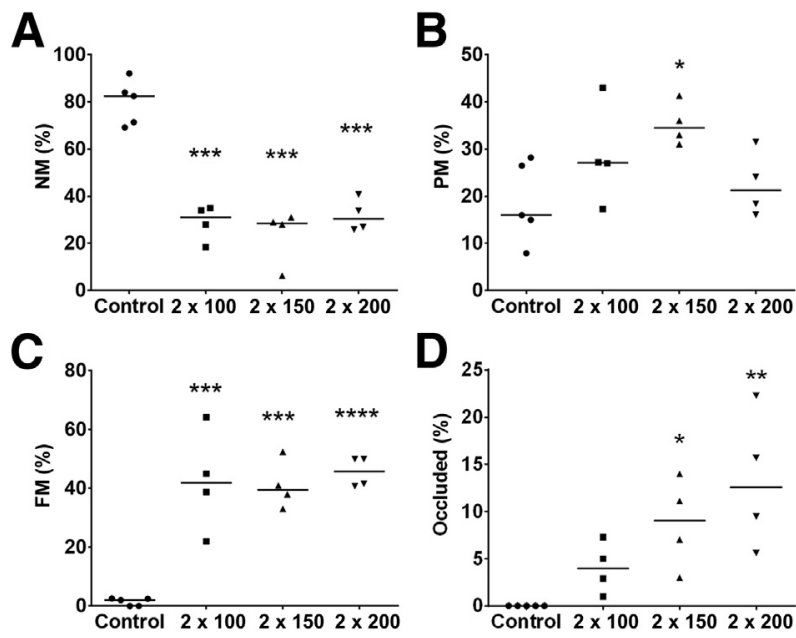

Figure 5 Dose-response study with fractioned lower doses of cyclophosphamide in female rats: $100,150,200$, and $250 \mathrm{mg} / \mathrm{kg}$ per week for 2 weeks $(2 \times 100,2 \times 150$, and $2 \times 200$, respectively), with sacrifice 4 weeks after the second injection. No rat survived to $250 \mathrm{mg} / \mathrm{kg}$ per week for 2 weeks $(2 \times 250)$ until 4 weeks. Muscularization of distal vessels (DVs; $<50 \mu \mathrm{m})$ was evaluated. Percentage of nonmuscularized (NM) DVs (A), partially muscularized (PM) DVs (B), fully muscularized (FM) DVs (C), and occluded DVs (D). ${ }^{*} P<0.05,{ }^{* *} P<0.01,{ }^{* * *} P<0.001$, and ${ }^{* * * *} P<0.0001$. 

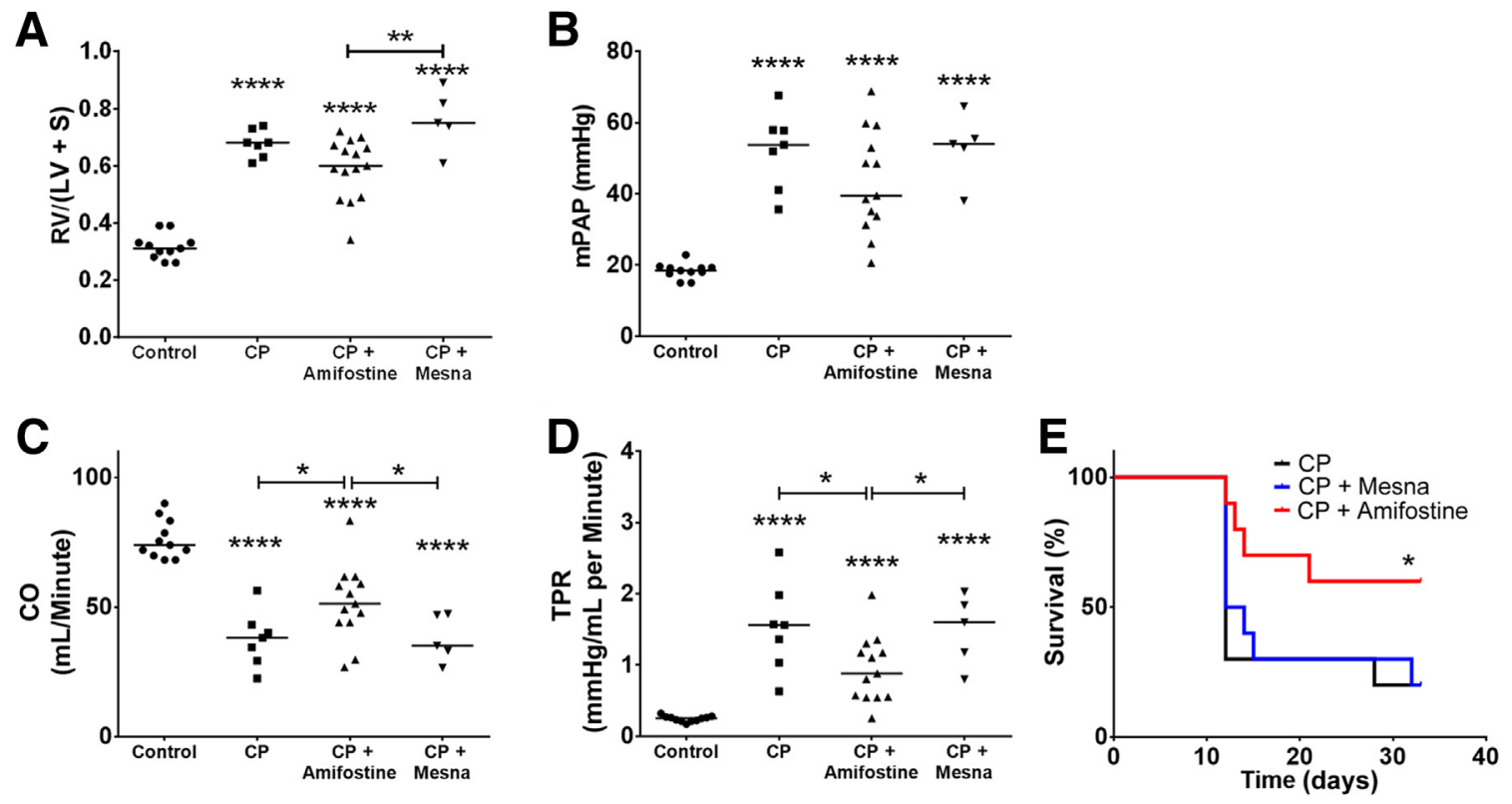

Figure 6 Cyclophosphamide (CP)-induced pulmonary hypertension is partially prevented by amifostine pretreatment, but not by mesna. Amifostine was given i.p. at $200 \mathrm{mg} / \mathrm{kg} 30$ minutes before $200 \mathrm{mg} / \mathrm{kg}$ per week for 2 weeks of CP. Mesna dose was given as i.p. injections in a dosage equal to $20 \%$ of CP dose at time of administration, 4 hours after each CP dose, and 8 hours after each CP dose. Animals were sacrificed 4 weeks after the second CP injection. Hemodynamic parameters, right heart hypertrophy, and survival were evaluated. A: Fulton index [right ventricle (RV)/left ventricle (LV) + septum (S) weight ratio]. B: Mean pulmonary artery pressure (mPAP; in $\mathrm{mmHg}$ ). C: Cardiac output (C0; in $\mathrm{mL} /$ minute). D: Total pulmonary resistances (TPRs; in $\mathrm{mmHg} / \mathrm{mL}$ per minute). E: Survival curves for $\mathrm{CP}, \mathrm{CP}+$ Mesna, and $\mathrm{CP}+$ Amifostine groups. ${ }^{*} P<0.05$, ${ }^{* * P}<0.01$, and ${ }^{* * * *} P<0.0001$.

respectively, according to the normality of the distribution. Survival was compared using the Mantel-Haenszel log-rank test. $P<0.05$ was considered statistically significant.

\section{Results}

\section{Characteristics of Suspected Chemotherapy-Related PVOD in the French PH Network and Systematic Review of the Literature}

In the French $\mathrm{PH}$ network, we identified 10 cases of chemotherapy-induced PVOD in the setting of anal cancer $(n=4)$, breast cancer $(n=2)$, lung cancer $(n=1)$, Hodgkin lymphoma $(n=2)$, and acute myeloblastic leukemia $(n=1)$. Demographic, functional, and hemodynamic characteristics of these patients are detailed in Table 1. Histological confirmation of PVOD after treatment with chemotherapy was obtained in one patient (Figure 1). Regarding the systematic literature review, we identified 179 eligible articles. After the adjudication process (online methods), a final consensus decision on the classification of PVOD was reached on the basis of clinical, functional, hemodynamic, radiological, and histological findings. Twenty-seven patients from 179 articles were considered to represent chemotherapy-induced PVOD. $^{5-10,12-28}$ Histological data were available in 22 $(81.5 \%)$ of 27 patients either by lung biopsy or autopsy, of which $20(74.1 \%)$ of 27 cases were classified as confirmed PVOD on the basis of compatible histological descriptions. The diagnosis of highly probable PVOD, on the basis of RHC and characteristic radiological signs on chest high-resolution computed tomography, was assigned to $4(14.8 \%)$ of 27 patients and probable PVOD was attributed to the remaining 3 (11.1\%) of 27 patients. Table 2 shows the demographic characteristics, type of underlying cancer, and chemotherapeutic regimen of the 27 PVOD patients identified in the literature. Combining all identified cases from the French $\mathrm{PH}$ network and literature review $(n=37)$, the median age of patients with chemotherapy-induced PVOD was 37.8 years (range, 2 to 66 years). No sex predominance was observed ( $45.9 \%$ males versus $54.1 \%$ females).

Regarding the underlying type of cancer, we separated solid malignancies from hematological disorders. Identified solid malignancies observed in the setting of developed PVOD were breast cancer $(n=2)$, brain malignancies $(n=3)$, including neuroblastoma $(n=1)$, astrocytoma $(n=1)$, and glioma $(n=1)$, cervical carcinoma $(n=2)$, lung cancer $(n=4)$, represented by different histological types [adenocarcinoma of the lung $(n=2)$, squamous lung cell cancer $(n=1)$, and large-cell lung carcinoma $(n=1)$ ], and anal cancer $(n=5)$. Hematological malignancies were acute lymphoblastic leukemia $(n=5)$, acute myeloid leukemia $(n=4)$, chronic myeloid leukemia $(n=1)$, multiple myeloma $(n=1)$, myeloproliferative and myelodysplastic syndrome $(n=1)$, and Hodgkin or non-Hodgkin lymphoma $(n=8)$.

\section{Chemotherapeutic Agents and Associated Therapy (Radiotherapy and BMT)}

From all identified cases in the French PH network and systematic review $(n=37)$, exposure to the following 

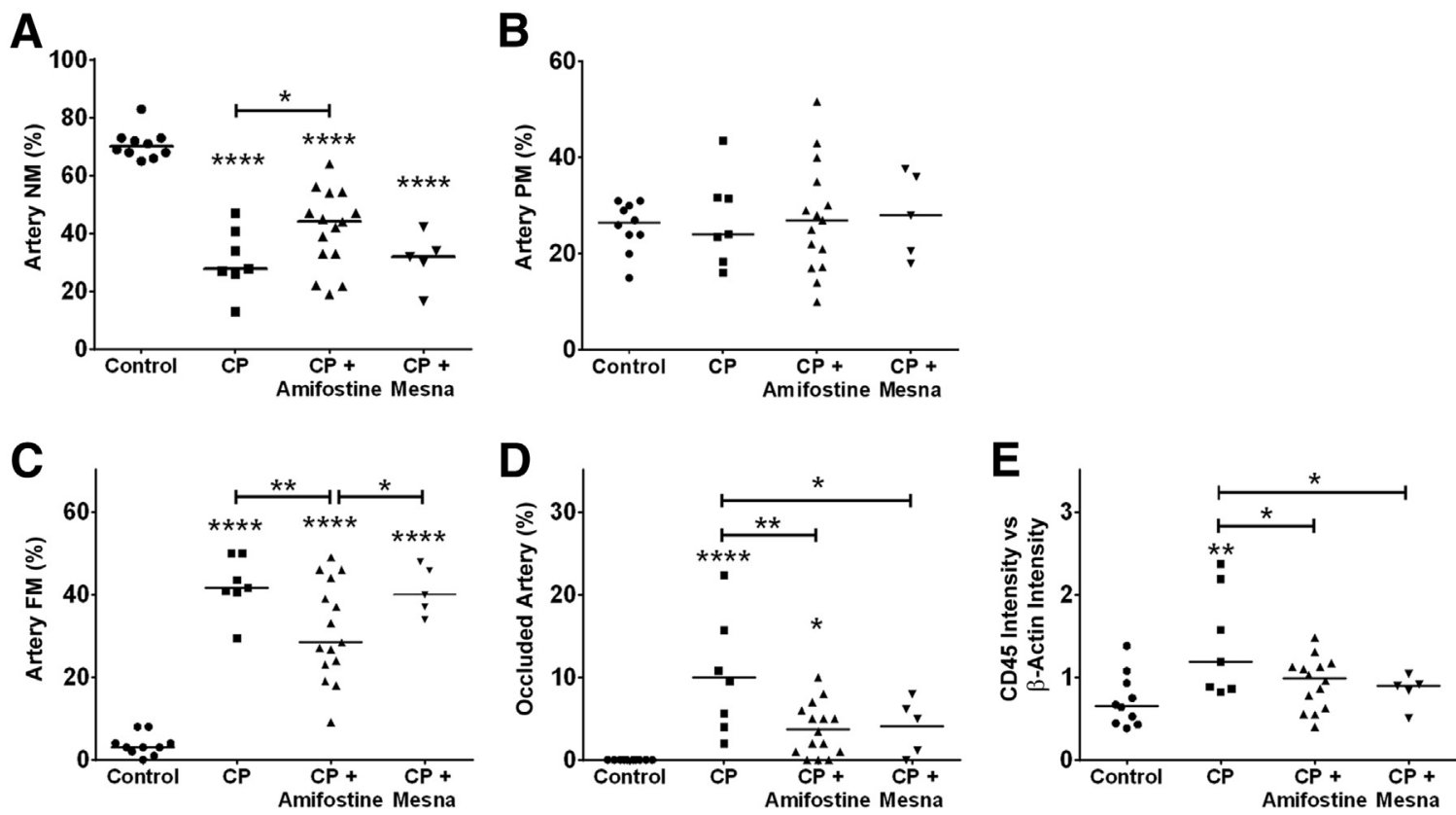

Figure 7 Cyclophosphamide (CP)-induced pulmonary vascular remodeling and inflammation are partially prevented by amifostine pretreatment, but not by mesna. Muscularization of distal vessels (DVs; $<50 \mu \mathrm{m}$ ) was evaluated. Percentage of nonmuscularized (NM) DVs (A), partially muscularized (PM) DVs (B), fully muscularized (FM) DVs (C), and occluded DVs (D). E: Quantification of the Western blot analysis of CD45 expression (pan-leukocyte marker) in whole lung

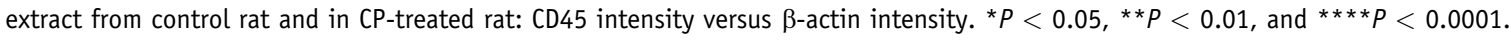

chemotherapeutic classes occurred before the development of PVOD (Table 3): alkylating agents or alkylating-like agents in $83.8 \%$ of cases, antimetabolites in $40.5 \%$ of cases, plant alkaloid and naturally occurring molecules in $45.9 \%$ of cases, and cytotoxic antibiotic and related molecules in $43.2 \%$ of cases. Alkylating or alkylating-like agents were mostly represented by CP (43.2\%), mitomycin (24.3\%), and cisplatin (21.6\%). In addition, $54 \%$ of all patients received additional radiotherapy, including total body irradiation in seven patients (18.9\%), thoracic radiotherapy in two patients (5.4\%), and local radiotherapy in 11 patients $(29.7 \%)$. Allogeneic stem cell transplantation has been proposed in eight patients (21.6\%), and autologous stem cell rescue was reported in five patients (13.5\%).

These results suggested that exposure to alkylating agents, in particular CP, was the most frequent risk factor observed in chemotherapy-induced PVOD. To confirm this observation, we conducted experiments using $\mathrm{CP}$ in three different animal models (mouse, rat, and rabbit).

\section{CP Induces $\mathrm{PH}$ in Mouse}

When mice were injected with a single dose of $350 \mathrm{mg} / \mathrm{kg}$ $\mathrm{CP}$, they developed PH without an apparent sex difference. This was attested 4 weeks later by a significant increase in right ventricular systolic pressure and by compensatory $\mathrm{RVH}$ quantified by the Fulton index $[\mathrm{RV} /(\mathrm{LV}+\mathrm{S})]$ (Figure 2, A-D). This macroscopic heart effect was specific to the RV because only the ratio of RV/body weight increased after CP exposure, but not the ratio of LV/body weight. Histologically, we observed septal thickening and accumulation of large foamy intra-alveolar macrophages (Figure 2, E and F).

Pulmonary Vascular Remodeling, Endothelial Dysfunction, and Effects of Cytoprotective Agents on CP-Induced PH in Rat

In rats, there was a sex difference in response to a single injection of $350 \mathrm{mg} / \mathrm{kg} \mathrm{CP}$. Females developed severe and homogeneous $\mathrm{PH}$ after 4 weeks of treatment characterized by marked RVH (Supplemental Figure S1), whereas males developed heterogeneous $\mathrm{PH}$ ranging from nonaffected to severely affected animals. Histologically, affected animals had distal muscularization of normally nonmuscularized microvessels (arterioles and venules; $<50 \mu \mathrm{m}$ ) (Figure 3, B, $\mathrm{C}, \mathrm{E}$, and F). This was associated with medial hypertrophy of more proximal muscularized pulmonary arteries (Figure 3, A-D). After this initial study, we, therefore, chose females to analyze the kinetics of $\mathrm{PH}$ development after a single $350 \mathrm{mg} / \mathrm{kg} \mathrm{CP}$ exposure over a 4-week period.

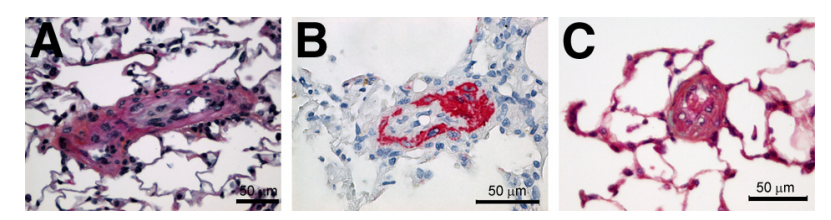

Figure 8 Thirteen weeks of repeated low-dose $(100 \mathrm{mg} / \mathrm{kg})$ cyclophosphamide (CP) exposure induces intimal thickening (A and $\mathbf{B}$ ) with sometimes the presence of recanalized small pulmonary vessels (C). A and C: Hematein-eosin-safran stain. B: $\alpha$-Smooth muscle actin immunohistochemical staining (red) with hematoxylin counterstaining (blue). 

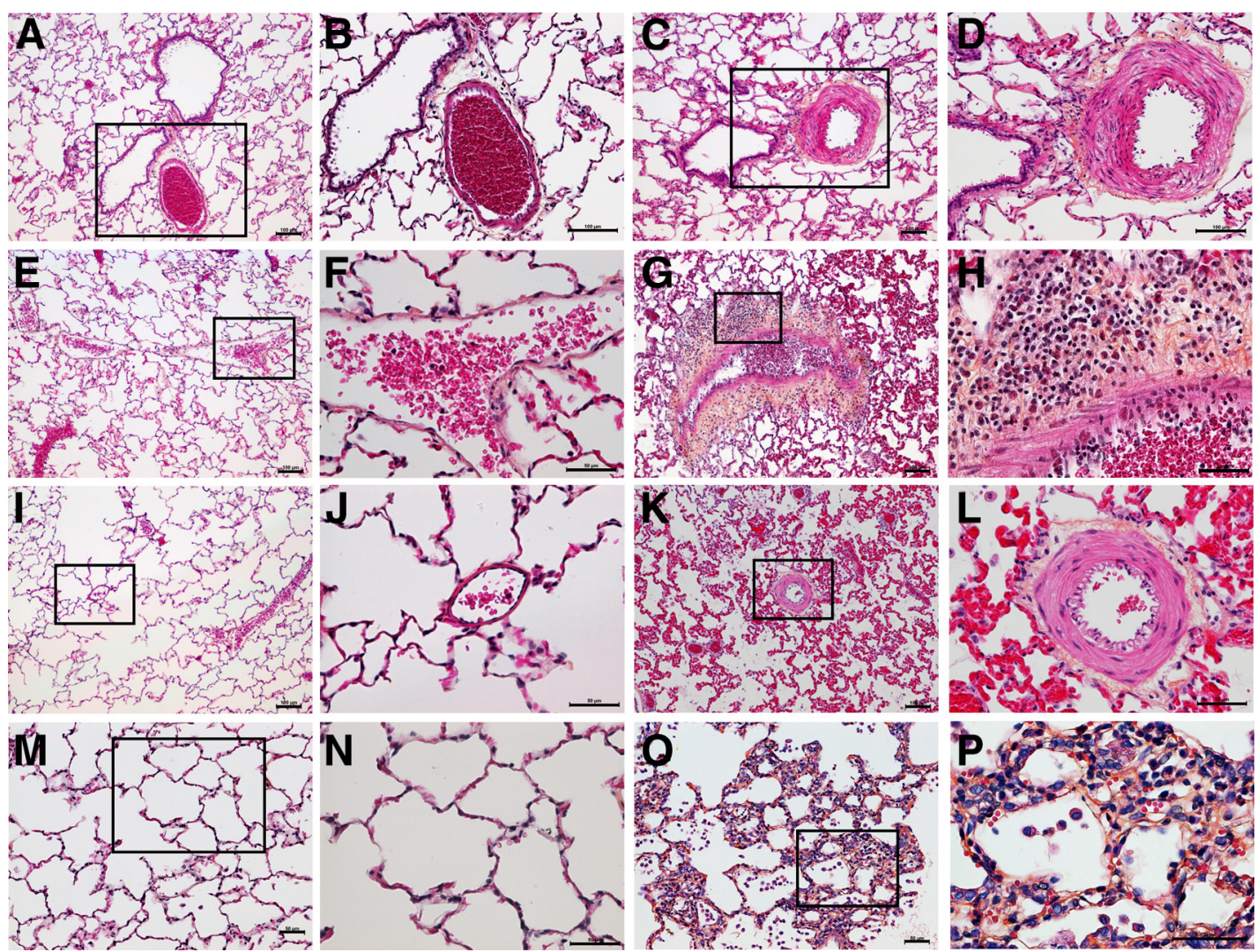

Figure 9 Cyclophosphamide (CP) induces pulmonary hypertension in rabbits with signs of vein-related vasculopathy. A-P: Representative images of the pulmonary precapillary and post-capillary and capillary vessels of nonexposed $(\mathbf{A}, \mathbf{B}, \mathbf{E}, \mathbf{F}, \mathbf{I}, \mathbf{J}, \mathbf{M}$, and $\mathbf{N})$ and $\mathbf{C P}$-exposed $(\mathbf{C}, \mathbf{D}, \mathbf{G}, \mathbf{H}, \mathbf{K}, \mathbf{L}, \mathbf{0}$, and $\mathbf{P})$ rabbits. C and $\mathbf{D}$ : $C P$ induces medial hypertrophy of muscular pulmonary arteries (PAs) compared to the thin control PAs (A and $\mathbf{B})$. CP induces pulmonary vein (PV) wall thickening and PV adventitial and transmural inflammatory infiltration and fibrosis ( $\mathbf{G}$ and $\mathbf{H})$ compared to control PVs (E and $\mathbf{F})$. CP induces muscularization of distal microvessels with foci of pulmonary congestion ( $\mathbf{K}$ and $\mathbf{L}$ ) compared to control microvessels and parenchyma (I and $\mathbf{J})$. CP induces foci of septal hyperplasia and alveolar inflammation ( $\mathbf{O}$ and $\mathbf{P}$ ) compared to control alveoli and alveolar walls $(\mathbf{M}$ and $\mathbf{N})$. Hematein-eosin-safran stain was used. Boxed areas are shown at higher magnification in the panels to their right. Scale bars: $100 \mu \mathrm{m}(\mathbf{A}-\mathbf{E}, \mathbf{G}, \mathbf{I}$, and $\mathbf{K}) ; 50 \mu \mathrm{m}(\mathbf{F}, \mathbf{H}, \mathbf{J}$, and $\mathbf{L}-\mathbf{P})$.

We found that mean PA pressure and Fulton index were significantly increased 3 weeks after $\mathrm{CP}$ exposure and worsened further at 4 weeks (Supplemental Figure S2, A and B). The appearance of symptomatic $\mathrm{PH}$ at 3 weeks was preceded by an early and dramatic decrease in low-resistance NM distal microvessels at 1 week and, at the same time, an opposite large increase in partially muscularized distal microvessels. Subsequently, vascular remodeling continued to progress as the percentage of fully muscularized distal microvessels became significantly increased at 2 weeks and continued to increase at 3 and 4 weeks (Supplemental Figure S2, C-F). Early pulmonary vascular remodeling occurring at 1 and 2 weeks after $\mathrm{CP}$ exposure coincided with depletion of $\mathrm{T}$ - and B-lymphocyte populations in the peripheral blood (Supplemental Figure S3).

To reduce whole body toxicity of a single high dose of $350 \mathrm{mg} / \mathrm{kg} \mathrm{CP}$, we performed a dose-response study using fractionated doses in female rats at 100, 150, 200, and 250 $\mathrm{mg} / \mathrm{kg}$ per week for two doses, with sacrifice at 4 weeks after the second injection. No rat survived the highest dose to 4 weeks. All other doses induced PH with significant increase in Fulton index and mean PA pressure. A dose- response relationship to $\mathrm{CP}$ was observed, as evidenced by higher $\mathrm{CO}$, lower total pulmonary vascular resistances (Figure 4), and lower percentage of occluded distal microvessels $(>50 \mu \mathrm{m})$ (Figure 5) in the lower-dose groups. Serum vascular endothelial growth factor levels were increased across all dose ranges, endothelial dysfunction markers soluble E-selectin and vWF were elevated for the two highest doses, and finally, heart failure biomarker, B-type natriuretic peptide, was increased only for the 200 $\mathrm{mg} / \mathrm{kg}$ per week for 2 weeks (Supplemental Figure S4, A-D). No significant increases in other serum markers of endothelial dysfunction and inflammation (sICAM, monocyte chemoattractant protein-1, troponins $\mathrm{T}$ and $\mathrm{I}$, tissue inhibitor of matrix metalloproteinases type I, plasminogen activator inhibitor 1, myeloperoxidase, IL-6, and tumor necrosis factor $\alpha$ ) were detected. Last, we measured the level of serotonin (5-HT) in the lungs of control and CP-exposed rats by LC-MS/MS, given the recognized role of 5-HT in human $\mathrm{PH}$ pathogenesis. ${ }^{29} \mathrm{We}$ found that only the two highest doses of CP led to significant pathological pulmonary 5-HT accumulation (Supplemental Figure S4E). Hence, in the next step of the study, we used CP at $200 \mathrm{mg} / \mathrm{kg}$ per week for 2 
weeks as a model of severe CP-induced $\mathrm{PH}$ with right ventricular failure. It has recently been shown that heritable pulmonary arterial hypertension can be related to missense mutations in KCNK3 (the gene encoding KCNK3), resulting in loss of function, and the reduction in the potassium channel current. ${ }^{30}$ Accordingly, CP-induced pulmonary vascular dysfunction was associated with decreased expression of KCNK3 protein in the lungs (Supplemental Figure S5).

Mesna and amifostine are cytoprotective agents given in combination with chemotherapy to reduce normal tissue toxicity. Therefore, we assessed the potential prevention of CP-induced PH by these two cytoprotective agents ${ }^{31,32}$ using standard administration protocols. In the prevention study, amifostine, but not mesna, ameliorated $\mathrm{CP}$-induced $\mathrm{PH}$, with a notable improvement in survival and pulmonary hemodynamics (increase in $\mathrm{CO}$ with decrease in total peripheral vascular resistance) in $\mathrm{CP}+$ amifostin-treated rats (Figure 6). The decrease of total pulmonary resistance in $\mathrm{CP}+$ amifostintreated rats was linked to a decrease in resistive fully muscularized distal microvessels, and an increase in low-resistance NM-distal microvessels (Figure 7, A-C). The percentage of occluded distal microvessels was significantly lowered in both amifostine- and mesna-treated groups (Figure 7D). Inflammation, quantified by the total protein level of the pan-leukocyte marker CD45, was decreased in both cytoprotective strategies (Figure 7E). Both mesna and amifostine significantly decreased serum B-type natriuretic peptide levels, but had minor effects on vWF and soluble E-selectin levels (Supplemental Figure S6, A-C). However, only amifostine decreased the pathological pulmonary accumulation of 5-HT in CP-exposed animals (Supplemental Figure S6D). The lung protein level of KCNK3 in CP-exposed rats was not normalized by either amifostine or mesna (Supplemental Figure S7).

Finally, we assessed vascular remodeling after long-term exposure to CP. It has been shown in rat models of severe $\mathrm{PH}^{33}$ that pathognomonic angioproliferative lesions of human PAH (plexiform lesions) can only be obtained after 13 to 15 weeks of disease induction. Therefore, a lower dose of CP $(100 \mathrm{mg} / \mathrm{kg})$ was used to allow repeated injections of CP without premature death due to early heart failure. However, after 13 weeks of repeated low-dose CP exposure, we only observed intimal thickening and sporadic presence of recanalized small pulmonary vessels, but there was an absence of plexiform lesions (Figure 8).

\section{Pathological Assessment of CP-Induced PH in Rabbit}

On the basis of results obtained in rat, we challenged female rabbits. The maximal tolerated $\mathrm{CP}$ dose was $100 \mathrm{mg} / \mathrm{kg}$ per injection. Three injections of $\mathrm{CP}$ resulted in moderate $\mathrm{PH}$, confirmed by right heart hypertrophy measured by Fulton index (Supplemental Figure S8). Histologically, we found medial hypertrophy of muscular PA, neomuscularization of distal microvessels, and congestion and hyperplasia of septa. More important, there were significant thickening and adventitial fibrosis of pulmonary veins in association with a

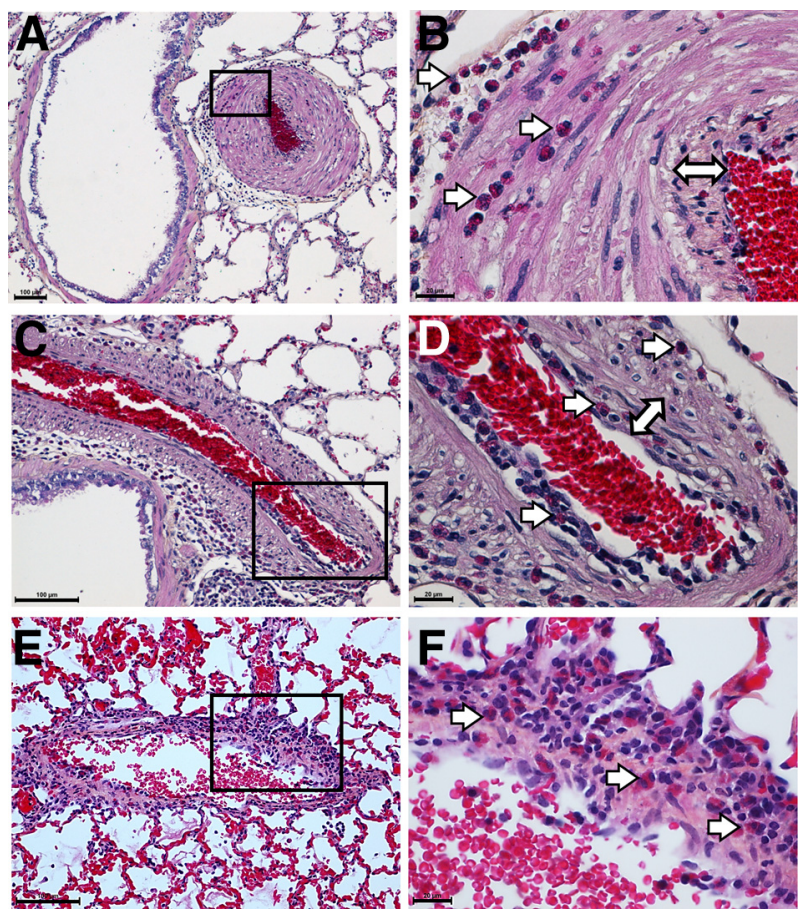

Figure 10 Pulmonary vascular eosinophilic inflammation was prominent in cyclophosphamide (CP)-exposed rabbits and was associated with severe vascular remodeling and intimal thickening. A and B: Transmural infiltration of eosinophils (arrows, B) in a pulmonary arterial lesion characterized by smooth muscle hyperplasia and intimal thickening (double-headed arrow, B). C and D: Accumulation of eosinophils in the subendothelial space of this pulmonary artery inflammatory neointimal lesion. Note eosinophils (arrows, D) and neointima (double-headed arrow, D). Note also the adventitial accumulation of eosinophils in both lesions. $\mathbf{E}$ and F: Small vein displaying fibrous remodeling (orange $=$ collagen) and significant eosinophilic infiltrate (arrows, F). Hematein-eosin-safran stain was used. Boxed areas are shown at higher magnification in the panels to their right. Scale bars: $100 \mu \mathrm{m}$ (A, C, and E); $20 \mu \mathrm{m}$ (B, D, and F).

pronounced vasculitis (Figure 9). These pathological changes are consistent with venular remodeling resembling venoocclusive disease. Pulmonary vascular eosinophilic inflammation was prominent in CP-exposed rabbits, leading to severe vascular remodeling and intimal thickening (Figure 10). $\mathrm{CP}$-induced $\mathrm{PH}$ in rabbit was associated with a significant increase in plasma endothelin-1 levels, a potent vasoconstrictor involved in human PAH (Supplemental Figure S9).

\section{Discussion}

Our systematic review and experience of the French $\mathrm{PH}$ network suggest that alkylating and alkylating-like agents represent a risk factor for the development of PVOD. In experimental models, $\mathrm{CP}$ exposure induced $\mathrm{PH}$ in three different animal models: mouse, rat, and rabbit. In rats, the severity of $\mathrm{PH}$ and vascular remodeling was sex dependent (females were more susceptible than males), time dependent, and dose dependent. We also demonstrate in rats that amifostine pretreatment improved survival and ameliorated $\mathrm{PH}$ severity after $\mathrm{CP}$ exposure. Mesna did not appear to share the 
same cytoprotective effects on the pulmonary vasculature. Rabbits exposed to $\mathrm{CP}$ displayed features of congestive lungs and venular involvement, mimicking human PVOD. In mice, it has been shown previously that a single injection of CP can produce pulmonary toxicity characterized by accumulation of intra-alveolar macrophages and diffuse progressive interstitial fibrosis. ${ }^{34} \mathrm{We}$ demonstrate, for the first time, that $\mathrm{CP}$ can also induce pulmonary vascular remodeling and $\mathrm{PH}$ in mice.

The similarity of endothelial cell response to different bifunctional alkylating agents suggests that DNA crosslinking may inhibit cell proliferation and thereby limit the repair capacity of endothelial monolayers. This might contribute to the progressive pulmonary vascular injury that occurs after administration of certain DNA cross-linking agents in vivo. ${ }^{35}$ The pattern of pulmonary endothelial cell injury induced by chemotherapy agents is reminiscent of that seen after treatment with another well-known bifunctional alkylating agent, monocrotaline pyrrole (the active metabolite of monocrotaline), which is commonly used to trigger experimental $\mathrm{PH}$ in rats. ${ }^{35} \mathrm{CP}$ is a common component of multidrug regimens, with a high potential for pulmonary toxicity, and has been reported to cause acute and chronic pulmonary injury in both humans and animals. The activities of the enzymes involved in the metabolism of CP show significant tissue selectivity, and the lack of detoxifying enzymes, such as aldehyde oxidase and aldehyde dehydrogenase, in the lungs accounts for selective CP toxicity in lung tissue. ${ }^{36}$ Furthermore, it has been demonstrated that endothelial cells are more susceptible to the effects of $\mathrm{CP}$ than other cell types. ${ }^{37,38}$ Previous in vitro studies with $\mathrm{CP}$, busulfan, azathioprine, monocrotaline, and dacarbazine suggest that these drugs can cause hepatic veno-occlusive disease by targeting sinusoidal endothelial cells via glutathione (GSH) depletion. ${ }^{39,40}$ Rats exposed to CP show reduced pulmonary GSH content, glucose-6-phosphate dehydrogenase, GSH reductase, GSH peroxidase, and superoxide dismutase activities. Therefore, one mechanism of pulmonary toxicity of CP could be mediated by oxidative damage.

The present article represents the largest systematic review of the literature regarding the possible association between PVOD and chemotherapeutic agents. Most of the patients were treated by different chemotherapeutic agents and, therefore, a clear relationship between specific drug use and PVOD is difficult to establish. Nevertheless, on the basis of observations from the literature review, alkylating agents are often identified to be associated with the development of PVOD. The identification of alkylating agents could also be linked to the fact that these drugs are frequently used in the treatment of solid or hematological malignancies. However, the frequent identification of alkylating agents, mainly represented by $\mathrm{CP}$ and mitomycin, suggests a likely relationship between PVOD and exposure to these agents. The analysis of case reports in the literature was based on clinical, functional, histopathological, and hemodynamic parameters. The diagnosis of PAH and PVOD is sometimes difficult to distinguish because of similar clinical presentation and overlapping histological changes. However, all reported cases were reviewed by experts of different specialties, and histological confirmation was present in $>50 \%$ of cases.

In our experimental models of CP exposure, the development of $\mathrm{PH}$ was associated with pulmonary venous remodeling. Although lung injury leading to interstitial fibrosis is a well-documented potential complication of various chemotherapeutic agents, the association between vascular injury and $\mathrm{CP}$ represents a novel finding. The pathophysiological features of PVOD in the setting of chemotherapy and the mechanisms leading to pulmonary venous remodeling and capillary proliferation are largely unknown. ${ }^{41}$ Recently, it has been demonstrated that a heritable form of PVOD is due to biallelic mutation of the EIF2AK4 gene. ${ }^{42}$ EIF2AK4 gene codes for GCN2, a serinethreonine kinase that can induce changes in gene expression in response to amino acid deprivation. ${ }^{42}$ The role and expression of GCN2 in the pulmonary vasculature are largely unknown; however, a decrease of GCN2 activity may lead to an increase in vulnerability to oxidative stress and an increase in inflammation. ${ }^{43} \operatorname{EIF} 2 A K 4$ (-/-) knockout mice have been shown to display increased susceptibility to both acute or chronic liver damage induced by carbon tetrachloride, which is accompanied by increased necrosis and greater inflammatory infiltrates compared to wild-type mice. ${ }^{44}$ Interestingly, we also noted a pronounced vasculitis of small pulmonary veins in CP-exposed animals. Because only a minority of patients treated with alkylating agents will develop PVOD, further studies on genetic susceptibility and the role of GCN2 in human chemotherapy-induced PVOD are required.

It is paradoxical that $\mathrm{CP}$ has been used in clinical practice, with therapeutic success for PAH in the setting of inflammatory conditions, such as systemic lupus erythematosis and mixed connective tissue disease. ${ }^{45,46}$ We can speculate that $\mathrm{CP}$ might reverse $\mathrm{PAH}$ when associated with inflammatory conditions, but it may induce PVOD in subjects with underlying susceptibility. As an analogy, such paradoxical effects have also been observed with dasatinib, a dual Src/ $\mathrm{Abl}$ kinase inhibitor, which is able to reverse experimental $\mathrm{PH}$ but induces PAH in humans. ${ }^{47}$

In conclusion, we demonstrate a plausible cause-effect relationship between PVOD and chemotherapeutic agents. From our exhaustive review of the literature and French PH network, alkylating or alkylating-like agents are particularly implicated in chemotherapy-induced PH. In this context, we evaluated different experimental models of $\mathrm{PH}$ and demonstrated that $\mathrm{CP}$, an alkylating agent, can induce $\mathrm{PH}$ with pulmonary venous involvement. Clinicians should be aware of this uncommon, but severe, pulmonary vascular complication of alkylating agents.

\section{Acknowledgments}

We thank Nicolas Favrolt, Vincent Cottin, Pascal Magro, Laurent Têtu for help analyzing the data from the French $\mathrm{PH}$ 
Registry; Bernadette Lescure and Nadège Brunel (INSERM IFR 65, Plateforme de Microdosages, Paris, France) for assistance in carrying over Milliplex analyses; and Audrey Solgadi and Stéphanie Nicolay (Service d'Analyse des Médicaments et Métabolites, Mass Spectrometry facility of Institut Paris-Sud d'Innovation Thérapeutique-Paris Sud University) for help in setting up the liquid chromatographymass spectrometry method.

\section{Supplemental Data}

Supplemental material for this article can be found at http://dx.doi.org/10.1016/j.ajpath.2014.10.021.

\section{References}

1. Simonneau G, Gatzoulis MA, Adatia I, Celermajer D, Denton C, Ghofrani A, Gomez Sanchez MA, Krishna Kumar R, Landzberg M, Machado RF, Olschewski H, Robbins IM, Souza R: Updated clinical classification of pulmonary hypertension. J Am Coll Cardiol 2013, 62: D34-D41

2. Nicod P, Moser KM: Primary pulmonary hypertension: the risk and benefit of lung biopsy. Circulation 1989, 80:1486-1488

3. Montani D, Achouh L, Dorfmüller P, Le Pavec J, Sztrymf B, Tchérakian C, Rabiller A, Haque R, Sitbon O, Jaïs X, Dartevelle P, Maître S, Capron F, Musset D, Simonneau G, Humbert M: Pulmonary veno-occlusive disease: clinical, functional, radiologic, and hemodynamic characteristics and outcome of 24 cases confirmed by histology. Medicine (Baltimore) 2008, 87:220-233

4. Perros F, Cohen-Kaminsky S, Gambaryan N, Girerd B, Raymond N, Klingelschmitt I, Huertas A, Mercier O, Fadel E, Simonneau G, Humbert M, Dorfmüller P, Montani D: Cytotoxic cells and granulysin in pulmonary arterial hypertension and pulmonary veno-occlusive disease. Am J Respir Crit Care Med 2013, 187:189-196

5. Joselson R, Warnock M: Pulmonary veno-occlusive disease after chemotherapy. Hum Pathol 1983, 14:88-91

6. Knight BK, Rose AG: Pulmonary veno-occlusive disease after chemotherapy. Thorax 1985, 40:874-875

7. Swift GL, Gibbs A, Campbell IA, Wagenvoort CA, Tuthill D: Pulmonary veno-occlusive disease and Hodgkin's lymphoma. Eur Respir J 1993, 6:596-598

8. Salzman D, Adkins DR, Craig F, Freytes C, LeMaistre CF: Malignancy-associated pulmonary veno-occlusive disease: report of a case following autologous bone marrow transplantation and review. Bone Marrow Transplant 1996, 18:755-760

9. Kuga T, Kohda K, Hirayama Y, Matsumoto S, Nakazawa O, Ando M, Ezoe A, Nobuoka A, Mochizuki C: Pulmonary veno-occlusive disease accompanied by microangiopathic hemolytic anemia 1 year after a second bone marrow transplantation for acute lymphoblastic leukemia. Int J Hematol 1996, 64:143-150

10. Troussard X, Bernaudin JF, Cordonnier C, Fleury J, Payen D, Briere J, Vernant JP: Pulmonary veno-occlusive disease after bone marrow transplantation. Thorax 1984, 39:956-957

11. Kay JM: Comparative morphologic features of the pulmonary vasculature in mammals. Am Rev Respir Dis 1983, 128:S53-S57

12. Kramer MR, Estenne M, Berkman N, Antoine M, de Francquen P, Lipski A, Jacobovitz D, Lafair J: Radiation-induced pulmonary venoocclusive disease. Chest 1993, 104:1282-1284

13. Williams LM, Fussell S, Veith RW, Nelson S, Mason CM: Pulmonary veno-occlusive disease in an adult following bone marrow transplantation: case report and review of the literature. Chest 1996, 109: $1388-1391$
14. Capewell SJ, Wright AJ, Ellis DA: Pulmonary veno-occlusive disease in association with Hodgkin's disease. Thorax 1984, 39:554-555

15. Trobaugh-Lotrario AD, Greffe B, Deterding R, Deutsch G, Quinones R: Pulmonary veno-occlusive disease after autologous bone marrow transplant in a child with stage IV neuroblastoma: case report and literature review. J Pediatr Hematol Oncol 2003, 25: 405-409

16. Gagnadoux F, Capron F, Lebeau B: Pulmonary veno-occlusive disease after neoadjuvant mitomycin chemotherapy and surgery for lung carcinoma. Lung Cancer 2002, 36:213-215

17. Vansteenkiste JF, Bomans P, Verbeken EK, Nackaerts KL, Demedts MG: Fatal pulmonary veno-occlusive disease possibly related to gemcitabine. Lung Cancer 2001, 31:83-85

18. Malhotra P, Varma S, Varma N, Sharma RR, Jain S, Kumari S, Manoj R, Marwaha N: Pulmonary veno-occlusive disease as a cause for reversible pulmonary hypertension in a patient with multiple myeloma undergoing peripheral blood stem cell transplantation. Am J Hematol 2005, 80:164-165

19. Willems E, Canivet J-L, Ghaye B, de Leval L, Radermecker M, Preiser J-C, Beguin Y: Pulmonary veno-occlusive disease in myeloproliferative disorder. Eur Respir J 2009, 33:213-216

20. Lombard CM, Churg A, Winokur S: Pulmonary veno-occlusive disease following therapy for malignant neoplasms. Chest 1987, 92:871-876

21. Hosokawa K, Yamazaki H, Nishitsuji M, Kobayashi S, Takami A, Fujimura M, Nakao S: Pulmonary veno-occlusive disease following reduced-intensity allogeneic bone marrow transplantation for acute myeloid leukemia. Intern Med 2012, 51:195-198

22. Hackman RC, Madtes DK, Petersen FB, Clark JG: Pulmonary venoocclusive disease following bone marrow transplantation. Transplantation 1989, 47:989-992

23. Seguchi M, Hirabayashi N, Fujii Y, Azuno Y, Fujita N, Takeda K, Sato Y, Nishimura M, Yamada K, Oka Y: Pulmonary hypertension associated with pulmonary occlusive vasculopathy after allogeneic bone marrow transplantation. Transplantation 2000, 69: $177-179$

24. Gutman JA, Allen CT, Madtes DK, Schramm J, Delaney C: Pulmonary veno-occlusive disease following reduced-intensity cord blood transplantation. Bone Marrow Transplant 2008, 42:559-561

25. Nakaoka H, Sakata Y, Yamamoto M, Maeda T, Arita Y, Shioyama W, Nakaoka Y, Kanakura Y, Yamashita S, Komuro I, YamauchiTakihara K: Pulmonary hypertension associated with bone marrow transplantation. J Cardiol Cases 2010, 2:e23-e27

26. Miyata D, Fukushima T, Matsunaga M, Saito N, Kato Y, TakahashiIgari M, Horigome H, Sumazaki R, Yamaki S, Matsui A: Fatal pulmonary veno-occlusive disease after chemotherapy for Burkitt's lymphoma. Pediatr Int 2011, 53:403-405

27. Mukai M, Kondo M, Bohgaki T, Notoya A, Kohno M: Pulmonary veno-occlusive disease following allogeneic peripheral blood stem cell transplantation for chronic myeloid leukaemia. Br J Haematol 2003, 123:1

28. Pathak V, Ford HJ, Rojas-Balcazar J, Kuhn J: Pulmonary venoocclusive disease (PVOD) after chemotherapy in a patient with anal cancer. Am J Respir Crit Care Med 2012, 185:A6180

29. Humbert M, Montani D, Perros F, Dorfmüller P, Adnot S, Eddahibi S: Endothelial cell dysfunction and cross talk between endothelium and smooth muscle cells in pulmonary arterial hypertension. Vascul Pharmacol 2008, 49:113-118

30. Ma L, Roman-Campos D, Austin ED, Eyries M, Sampson KS, Soubrier F, Germain M, Trégouët D-A, Borczuk A, Rosenzweig EB, Girerd B, Montani D, Humbert M, Loyd JE, Kass RS, Chung WK: A novel channelopathy in pulmonary arterial hypertension. N Engl J Med 2013, 369:351-361

31. Bryant BM, Jarman M, Ford HT, Smith IE: Prevention of isophosphamide-induced urothelial toxicity with 2-mercaptoethane sulphonate sodium (mesnum) in patients with advanced carcinoma. Lancet 1980, 2:657-659 
32. Spencer CM, Goa KL: Amifostine: a review of its pharmacodynamic and pharmacokinetic properties, and therapeutic potential as a radioprotector and cytotoxic chemoprotector. Drugs 1995, 50: $1001-1031$

33. Abe K, Toba M, Alzoubi A, Ito M, Fagan KA, Cool CD, Voelkel NF, McMurtry IF, Oka M: Formation of plexiform lesions in experimental severe pulmonary arterial hypertension. Circulation 2010, 121:2747-2754

34. Morse CC, Sigler C, Lock S, Hakkinen PJ, Haschek WM, Witschi HP: Pulmonary toxicity of cyclophosphamide: a 1-year study. Exp Mol Pathol 1985, 42:251-260

35. Hoorn CM, Wagner JG, Petry TW, Roth RA: Toxicity of mitomycin C toward cultured pulmonary artery endothelium. Toxicol Appl Pharmacol 1995, 130:87-94

36. Cooper JA Jr, Merrill WW, Reynolds HY: Cyclophosphamide modulation of bronchoalveolar cellular populations and macrophage oxidative metabolism: possible mechanisms of pulmonary pharmacotoxicity. Am Rev Respir Dis 1986, 134:108-114

37. Hamano Y, Sugimoto H, Soubasakos MA, Kieran M, Olsen BR, Lawler J, Sudhakar A, Kalluri R: Thrombospondin-1 associated with tumor microenvironment contributes to low-dose cyclophosphamidemediated endothelial cell apoptosis and tumor growth suppression. Cancer Res 2004, 64:1570-1574

38. Ohtani T, Nakamura T, Toda K-I, Furukawa F: Cyclophosphamide enhances TNF-alpha-induced apoptotic cell death in murine vascular endothelial cell. FEBS Lett 2006, 580:1597-1600

39. DeLeve LD: Cellular target of cyclophosphamide toxicity in the murine liver: role of glutathione and site of metabolic activation. Hepatology 1996, 24:830-837

40. Srivastava A, Poonkuzhali B, Shaji RV, George B, Mathews V, Chandy M, Krishnamoorthy R: Glutathione S-transferase M1 polymorphism: a risk factor for hepatic venoocclusive disease in bone marrow transplantation. Blood 2004, 104:1574-1577

41. Montani D, Price LC, Dorfmuller P, Achouh L, Jaïs X, Yaïci A, Sitbon O, Musset D, Simonneau G, Humbert M: Pulmonary venoocclusive disease. Eur Respir J 2009, 33:189-200

42. Eyries M, Montani D, Girerd B, Perret C, Leroy A, Lonjou C, Chelghoum N, Coulet F, Bonnet D, Dorfmüller P, Fadel E, Sitbon O, Simonneau G, Tregouët D-A, Humbert M, Soubrier F: EIF2AK4 mutations cause pulmonary veno-occlusive disease, a recessive form of pulmonary hypertension. Nat Genet 2014, 46:65-69

43. Wilson GJ, Bunpo P, Cundiff JK, Wek RC, Anthony TG: The eukaryotic initiation factor 2 kinase GCN2 protects against hepatotoxicity during asparaginase treatment. Am J Physiol Endocrinol Metab 2013, 305:E1124-E1133

44. Arriazu E, Ruiz de Galarreta M, López-Zabalza MJ, Leung TM, Nieto N, Iraburu MJ: GCN2 kinase is a key regulator of fibrogenesis and acute and chronic liver injury induced by carbon tetrachloride in mice. Lab Invest 2013, 93:303-310

45. Jais X, Launay D, Yaici A, Le Pavec J, Tchérakian C, Sitbon O, Simonneau G, Humbert M: Immunosuppressive therapy in lupus- and mixed connective tissue disease-associated pulmonary arterial hypertension: a retrospective analysis of twenty-three cases. Arthritis Rheum 2008, 58:521-531

46. Sanchez O, Sitbon O, Jaïs X, Simonneau G, Humbert M: Immunosuppressive therapy in connective tissue diseases-associated pulmonary arterial hypertension. Chest 2006, 130:182-189

47. Montani D, Bergot E, Günther S, Savale L, Bergeron A, Bourdin A, Bouvaist H, Canuet M, Pison C, Macro M, Poubeau P, Girerd B, Natali D, Guignabert C, Perros F, O'Callaghan DS, Jaïs X, Tubert-Bitter P, Zalcman G, Sitbon O, Simonneau G, Humbert M: Pulmonary arterial hypertension in patients treated by dasatinib. Circulation 2012, 125:2128-2137 